\title{
catalysts
}

ISSN 2073-4344

www.mdpi.com/journal/catalysts

Article

\section{Inhibition of a Gold-Based Catalyst in Benzyl Alcohol Oxidation: Understanding and Remediation}

\section{Emmanuel Skupien ${ }^{1}{ }^{*}$, Rob J. Berger ${ }^{2}$, Vera P. Santos ${ }^{1}$, Jorge Gascon ${ }^{1}$, Michiel Makkee ${ }^{1}$,} Michiel T. Kreutzer ${ }^{3}$, Patricia J. Kooyman ${ }^{1, *}$, Jacob A. Moulijn ${ }^{1}$ and Freek Kapteijn ${ }^{1}$

1 Catalysis Engineering, Chemical Engineering Department, Delft University of Technology, Julianalaan 136, 2628 BL Delft, The Netherlands; E-Mails: V.P.Santos@tudelft.nl (V.P.S.); J.Gascon@tudelft.nl (J.G.); M.Makkee@tudelft.nl (M.M.); J.A.Moulijn@tudelft.nl (J.A.M.); F.Kapteijn@tudelft.nl (F.K.)

2 Anaproc c/o Delft University of Technology, Julianalaan 136, 2628 BL Delft, The Netherlands; E-Mail: R.J.Berger@tudelft.nl

3 Product \& Process Engineering, Chemical Engineering Department, Delft University of Technology, Julianalaan 136, 2628 BL Delft, The Netherlands; E-Mail: M.T.Kreutzer@tudelft.nl

* Authors to whom correspondence should be addressed; E-Mails: E.Skupien@tudelft.nl (E.S.); P.J.Kooyman@tudelft.nl (P.J.K.); Tel.: +31-152-789-077 (P.J.K.); Fax: +31-152-785-006 (P.J.K.).

Received: 9 October 2013; in revised form: 26 January 2014 / Accepted: 26 March 2014 / Published: 15 April 2014

\begin{abstract}
Benzyl alcohol oxidation was carried out in toluene as solvent, in the presence of the potentially inhibiting oxidation products benzaldehyde and benzoic acid. Benzoic acid, or a product of benzoic acid, is identified to be the inhibiting species. The presence of a basic potassium salt $\left(\mathrm{K}_{2} \mathrm{CO}_{3}\right.$ or $\left.\mathrm{KF}\right)$ suppresses this inhibition, but promotes the formation of benzyl benzoate from the alcohol and aldehyde. When a small amount of water is added together with the potassium salt, an even greater beneficial effect is observed, due to a synergistic effect with the base. A kinetic model, based on the three main reactions and four major reaction components, is presented to describe the concentration-time profiles and inhibition. The inhibition, as well as the effect of the base, was captured in the kinetic model, by combining strong benzoic acid adsorption and competitive adsorption with benzyl alcohol. The effect of the potassium salt is accounted for in terms of neutralization of benzoic acid.
\end{abstract}


Keywords: gold; catalysis; benzyl alcohol; oxidation; deactivation; inhibition; mechanism; kinetics; modeling

\section{Introduction}

As far as the chemical industry is concerned, biomass is forecast to be one of the major successors of oil as a source of carbon for the production of organic molecules [1,2]. However, the chemistry of biomass-derived molecules differs significantly from oil-derived molecules $[1,3]$. Their higher oxygen content renders them more sensitive to oxidation, requiring milder conditions in selective oxidation processes. Furthermore, the solubility in water is enhanced when organics are oxygenated, which can be either problematic or advantageous. It is now widely recognized that the chemical industry will need to adapt to the new situation [1-3]. Once the catalytic abilities of gold had been discovered [4], its high activity for oxidation reactions at mild conditions, down to room temperature, was quickly noticed. This exceptionally low process temperature allows for a much better control over the selectivity, in particular in selective oxidations. These reactions play an important role in organic synthesis [1,5-11] and, as a consequence, much effort was put into studying and benchmarking gold-based catalysts for selective oxidation of alcohols, ketones, and carboxylic acids.

Benzyl alcohol $(\mathrm{BnOH})$ selective oxidation to benzaldehyde $(\mathrm{BnO})$ is one of these benchmark reactions used extensively to assess the catalytic activity of gold catalysts [1,5-9,11-13]. Alcohol selective oxidation is often carried out in the presence of a base as "promoter" or "co-catalyst" $[1-3,7,8,11,12,14,15]$. The base enhances the deprotonation of the alcohol, thereby ensuring that the rate-limiting step is the catalytic oxidation step [1,15]. Furthermore, alkaline conditions have also been reported to enhance the selectivity towards benzoic acid $(\mathrm{BnOOH})[1,15]$. However, the focus is usually on the initial turnover frequency (TOF) [5,7,12], whereas only a few reports mention issues of deactivation and re-usability $[1,6,9,11,14]$.

Deactivation can arise either from catalyst degradation (e.g., sintering) or from catalyst poisoning or fouling [16]. Poisoning and fouling can sometimes be reversed by catalyst regeneration, mainly under oxidative conditions [9]. Sulfur-containing impurities are often responsible for poisoning of noble metal catalysts [16], and desulfurization catalysis has matured for decades to answer this problem, for instance by a combination of hydrodesulphurization (HDS) and guard beds. In a more general perspective, poisoning impurities in the feed can be eliminated by dedicated treatments. In selective oxidation over noble metal catalysts, deactivation can also occur due to the over-oxidation of Pt [14] and Pd [14,17] catalysts when an excess of (molecular) oxygen is present. This over-oxidation means that too much atomic oxygen (a reaction intermediate) is present on the catalytic sites, thereby blocking their accessibility for hydrocarbon adsorption. Because of this, catalysts tested in the oxygen mass-transfer limited regime can exhibit higher activity $[1,11,14]$ than might be predicted based on data in the kinetic regime. It is generally accepted that gold-based catalysts are resistant to overoxidation $[1,3,11]$, making them promising candidates for oxidation reactions over extended periods of time. However, a reaction intermediate or the product itself can be an inhibiting entity. It should be noted that inhibition is reversible because the inhibition is remediated when the concentration of the 
inhibitor in the reaction medium is sufficiently reduced, whereas poisoning is irreversible at the reaction conditions [16]. This so-called product inhibition phenomenon is an even greater challenge, as the catalyst creates its own poison while performing the desired reaction. This has been frequently observed both in oxidation and dehydrogenation reactions. For instance, Dimitratos et al. [18] attributed deactivation of $\mathrm{Au}-\mathrm{Pd}$ and Au-Pt catalysts in octanol oxidation to inhibition by the carboxylate formed. They also reported the alleviation of this inhibition when $\mathrm{NaOH}$ was present. Zope and Davis [3] reported similar effects for the selective oxidation of glycerol to glyceric acid. They performed the reaction in the presence of 19 different compounds: either products or intermediates in the glycerol oxidation reaction, or species that might be formed from condensation of intermediates and/or products. Ketones, condensation products of ketones or secondary alcohols (forming ketones upon oxidation) were found to be inhibiting compounds. In contrast, simple carboxylic acids such as acetic acid and propionic acid did not show appreciable inhibition, nor did diacids such as malonic or succinic acid, or primary alcohols such as methanol. To the best of our knowledge, and despite reviews mentioning the occurrence of product inhibition during the oxidation of alcohols on gold and platinum group metal catalysts in general [11,14], no detailed study of this phenomenon for $\mathrm{BnOH}$ oxidation over gold-based catalysts has been reported.

The current study concerns the Au-catalyzed partial oxidation of $\mathrm{BnOH}$ to $\mathrm{BnO}$ and benzyl benzoate $(\mathrm{BnOOBn})$ in toluene over the commercial AUROlite ${ }^{\mathrm{TM}} \mathrm{Au} / \mathrm{Al}_{2} \mathrm{O}_{3}$ catalyst. $\mathrm{BnOH}$, which is a primary alcohol, is oxidized to $\mathrm{BnO}$ and subsequently to $\mathrm{BnOOH}$, while also $\mathrm{BnOOBn}$ can be formed (Figure 1). This system suffers from deactivation, which is particularly observed when the catalyst is re-used in batch-wise operation. This deactivation can be suppressed by the addition of an inorganic base. The aim of the current study is to analyze this deactivation process, identify the possible inhibiting species, elucidate the deactivation mechanism, and evaluate the beneficial effect of the inorganic base. To accomplish this, the reaction was carried out under various reaction conditions, including experiments in the presence of reaction products, bases, and water. Additionally, kinetic modeling was performed in order to confirm the reaction and deactivation mechanisms.

Figure 1. Reaction network: (a) oxidation of benzyl alcohol to benzaldehyde; (b) oxidation of benzaldehyde to benzoic acid; (c) esterification of benzyl alcohol and benzoic acid, and (d) esterification of benzyl alcohol and benzaldehyde under oxidative conditions to benzyl benzoate [19].

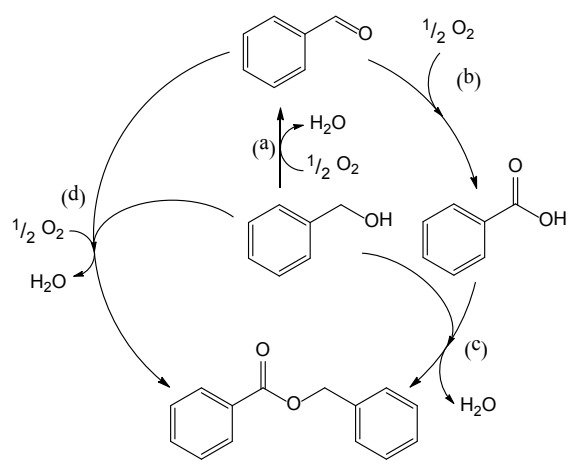




\section{Results and Discussion}

\subsection{Catalyst Deactivation in Base-Free Conditions}

Figure 2 displays the concentration profiles for two subsequent experiments performed under the same conditions and in the absence of a base. It should be noted that for all experimental data points, the mass balance of the 4 main components ( $\mathrm{BnOH}, \mathrm{BnO}, \mathrm{BnOOH}$ and $\mathrm{BnOOBn}$ ) closes to $100 \%$ within measurement errors, with rare exceptions where discrepancies up to $4 \%$ are present. Therefore, disproportionation and dehydration reactions, as reported by Alhumaimess et al. [5], can be neglected. In the first experiment, the initial TOF is $0.7 \mathrm{~s}^{-1}$ and conversion levels off at around 55-60\% after about $120 \mathrm{~min}$. The selectivity to $\mathrm{BnO}$ is $93 \%$, as reported in Table 1 . In view of the large discrepancies in TOF reported in literature [1], comparison of our data to previously published ones is not straightforward. It is satisfactory that the values of 0.6 to $0.8 \mathrm{~s}^{-1}$ reported in the present study are in the order of magnitude of those of 0.04 to $0.22 \mathrm{~s}^{-1}$ reported in the recent review by Davis et al. [1] for nanoparticulate gold and of 2.8 to $4.4 \mathrm{~s}^{-1}$ for a gold foil reported in the same review [1]. As indicated by Davis et al., the values span 2 orders of magnitude. The reason for this is most likely the wide range of reaction conditions used in different studies.

Figure 2. Catalyst performance in base-free conditions. Concentration of ( $\downarrow)$ benzyl alcohol, $(\boldsymbol{\square})$ benzaldehyde, $(\bullet)$ benzoic acid and $(\boldsymbol{\Delta})$ benzyl benzoate $v s$. reaction time for (a) first run using fresh AUROlite ${ }^{\mathrm{TM}}$ and (b) second run using spent AUROlite ${ }^{\mathrm{TM}}$. Reaction conditions: $T=80{ }^{\circ} \mathrm{C}, 0.8 \mathrm{~g}$ AUROlite ${ }^{\mathrm{TM}}, C_{\mathrm{BnOH}, \mathrm{t}=0}=3.0 \times 10^{-4} \mathrm{~mol} \cdot \mathrm{g}^{-1}$ in $80 \mathrm{~mL}$ of toluene, $200 \mathrm{~mL} \cdot \mathrm{min}^{-1}$ air flow. Concentrations are expressed in moles per unit mass of liquid in the reactor $\left(\mathrm{mol} \cdot \mathrm{g}^{-1}\right)$. The symbols with error bars are the experimental results and the lines represent the kinetic model.
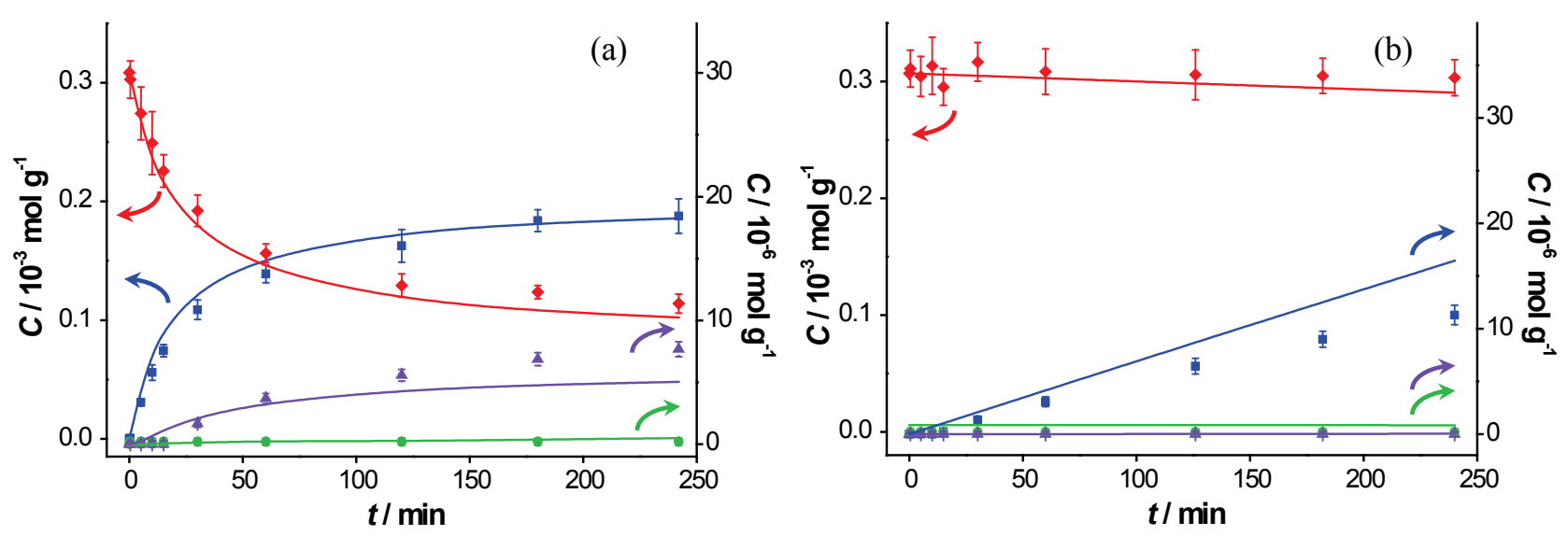
Table 1. Benzyl alcohol conversion rate, turn over frequency $(T O F)$, conversion at $240 \mathrm{~min}$ and selectivity to benzaldehyde at $60 \%$ conversion for AUROlite ${ }^{\mathrm{TM}}$ catalyst in different test conditions.

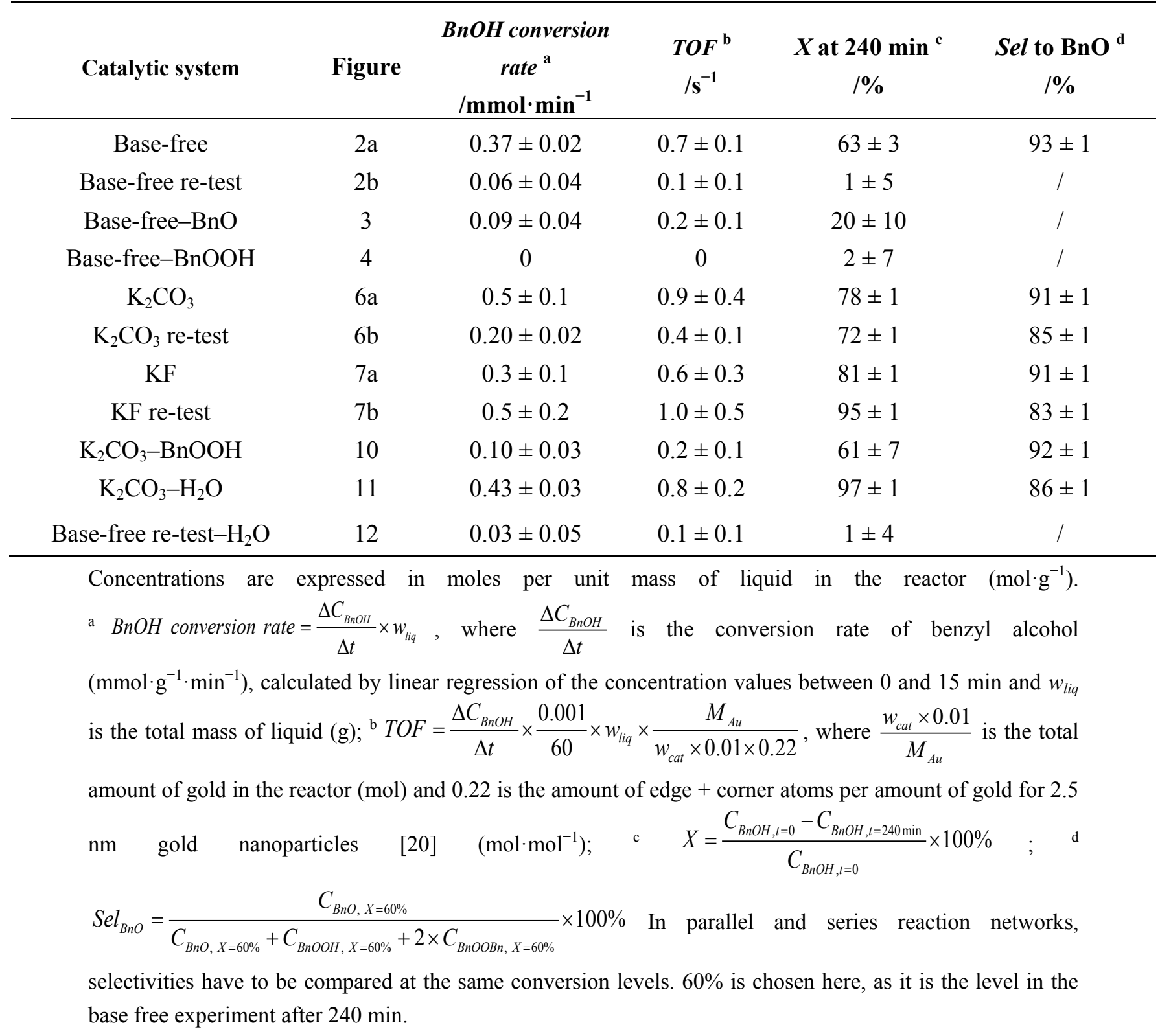

In the second experiment, which is identical to the first one but with re-use of the same catalyst sample after washing with toluene, virtually no conversion is observed, indicating that the catalyst was completely deactivated. Since no other reactants than toluene and benzyl alcohol were present in the reaction mixture, the deactivation must be caused either by catalyst deterioration or by an inhibitor formed during the first experiment.

The potential presence of sulfur-containing impurities was investigated by analyzing the toluene and benzyl alcohol by gas chromatography (GC). No sulfur-containing compounds could be detected, implying that their concentration was below $50 \mathrm{ppb}$ (the pulsed flame photometric detector (PFPD) detection limit). Accounting for the quantities of these chemicals introduced in the reaction mixture, this corresponds to $0.4 \mathrm{nmol}$ of sulfur components at maximum in the reactor. That is five orders of magnitude lower than the total amount of gold present. Since similar concentration profiles as shown 
in Figure 2 were obtained when using reagents that were pre-treated with activated carbon to remove any strongly adsorbing impurities, we conclude that feed contaminants, including sulfur compounds, are not responsible for the observed deactivation. As a consequence, activated carbon cleaning was deemed not to be necessary and was omitted for the experiments reported here.

These results thus suggest that products or intermediates formed cause the observed deactivation. In order to investigate whether product inhibition is indeed taking place, an experiment was performed with fresh catalyst, where $\mathrm{BnO}$ was added to the reactor $20 \mathrm{~min}$ prior to the actual start of the catalytic reaction under the same reaction conditions, i.e., before the introduction of $\mathrm{BnOH}$. The $20 \mathrm{~min}$ exposure time was selected based on the results of Figure 1a where it can be seen that BnOOBn was already formed at that reaction time, thereby ensuring that all potentially inhibiting products were present. The results in Figure 3 show a very low conversion of $20 \%$, confirming strong product inhibition. It is striking that despite the appreciable amount of $\mathrm{BnO}$ introduced at $t<0$, neither $\mathrm{BnOOBn}$ nor $\mathrm{BnOOH}$ could be detected until the $\mathrm{BnOH}$ was introduced at $t=0$. Clearly the sites for the sequential reactions of $\mathrm{BnO}$ (Figure 1a,b) are fully blocked without the presence of alcohol. It should be noted that for $t<0$ the $\mathrm{BnO}$ concentration shows a slight decrease, indicating that a small amount of $\mathrm{BnO}$ is consumed without producing a detectable amount of $\mathrm{BnOOH}$ in the liquid phase. We conclude that some product is formed which remains on the catalyst and inhibits further turnovers. Carboxylic acid moieties are well known to interact strongly with gold nanoparticle surfaces, even allowing the stabilization of small gold clusters in colloidal systems [21]. $\mathrm{BnOOH}$ is therefore suspected to be the inhibitor, since it is the logical product of $\mathrm{BnOH}$ oxidation, although its concentration in the solution stayed below the GC detection limit of $0.20 \mu \mathrm{mol} \cdot \mathrm{g}^{-1}$.

Figure 3. Catalyst performance after pre-addition of benzaldehyde. Concentration of $(\diamond)$ benzyl alcohol, $(\boldsymbol{\square})$ benzaldehyde, $(\bullet)$ benzoic acid and $(\boldsymbol{\Delta})$ benzyl benzoate $v s$. reaction time for catalytic reaction over fresh AUROlite ${ }^{\mathrm{TM}}$. Benzaldehyde was introduced $20 \mathrm{~min}$ before benzyl alcohol was added. Reaction conditions: $T=80{ }^{\circ} \mathrm{C}, 0.8 \mathrm{~g}$ AUROlite ${ }^{\mathrm{TM}}, C_{\mathrm{BnOH}}$, ${ }_{t=0}=3.0 \times 10^{-4} \mathrm{~mol} \cdot \mathrm{g}^{-1}, C_{\mathrm{BnO}, t<0}=1.7 \times 10^{-4} \mathrm{~mol} \cdot \mathrm{g}^{-1}$, in $80 \mathrm{~mL}$ of toluene, $200 \mathrm{~mL} \cdot \mathrm{min}^{-1}$ air flow. Concentrations are expressed in moles per unit mass of liquid in the reactor $\left(\mathrm{mol} \cdot \mathrm{g}^{-1}\right)$. The symbols with error bars are the experimental results and the lines represent the kinetic model.

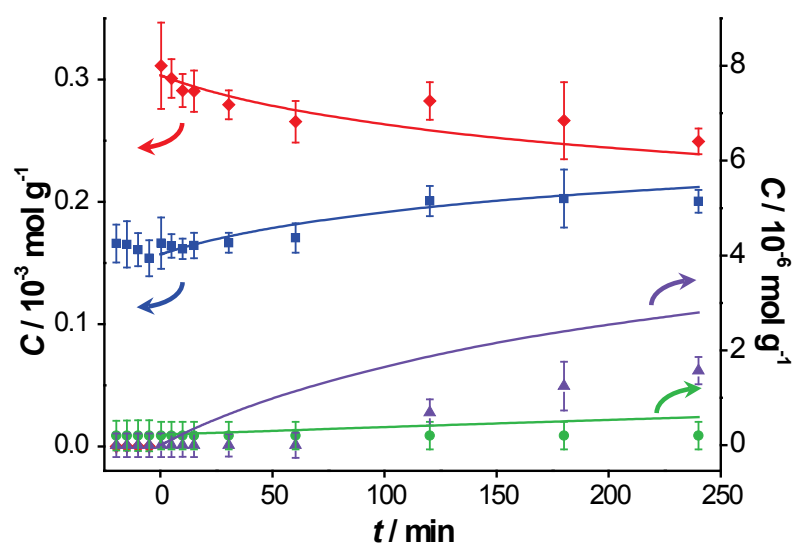


In order to evaluate the effect of $\mathrm{BnOOH}$, a similar experiment was performed in which $\mathrm{BnOOH}$ was added $20 \mathrm{~min}$ prior to the actual start of the test. The concentration profiles are shown in Figure 4. In this experiment, approximately 40 times less acid was introduced compared to the amount of aldehyde introduced for the experiment in Figure 3. Nevertheless, an even more dramatic inhibiting effect was observed: hardly any conversion of $\mathrm{BnOH}$ occurred. The concentration of $\mathrm{BnOOH}$ measured by GC at $t<0$ is $1 \mu \mathrm{mol} \cdot \mathrm{g}^{-1}$, which is about $25 \%$ of what was added, suggesting a strong interaction of $\mathrm{BnOOH}$ with the catalyst. The slight increase in concentration of $\mathrm{BnOOH}$ upon addition of $\mathrm{BnOH}$ at $t=0$ is attributed to competitive adsorption between the alcohol and the acid. No ester was present at the beginning of the reaction, nor was it detected during the course of the reaction. This suggests that the inhibiting product is either $\mathrm{BnOOH}$ or a compound formed from $\mathrm{BnOOH}$. Therefore, product inhibition particularly occurs on catalysts on which $\mathrm{BnO}$ can react further to $\mathrm{BnOOH}$. This interpretation is confirmed by a nanostructured gold-based catalyst synthesized in our lab exhibiting $100 \%$ selectivity to $\mathrm{BnO}$ not showing deactivation for 4 consecutive runs [22].

Figure 4. Catalyst performance after pre-addition of benzoic acid. Concentration of ( $\downarrow)$ benzyl alcohol, $(\boldsymbol{\square})$ benzaldehyde, $(\bullet)$ benzoic acid and $(\boldsymbol{\Delta})$ benzyl benzoate vs. reaction time for catalytic reaction over fresh AUROlite $^{\mathrm{TM}}$. Benzoic acid was introduced $20 \mathrm{~min}$ prior to the beginning of the reaction. Reaction conditions: $T=80{ }^{\circ} \mathrm{C}, 0.8 \mathrm{~g}$ AUROlite ${ }^{\mathrm{TM}}$, $C_{\mathrm{BnOH}, t=0}=3.0 \times 10^{-4} \mathrm{~mol} \cdot \mathrm{g}^{-1}, C_{\mathrm{BnOOH}, t<0}=4.1 \times 10^{-6} \mathrm{~mol} \cdot \mathrm{g}^{-1}$, in $80 \mathrm{~mL}$ of toluene, $200 \mathrm{~mL} \cdot \mathrm{min}^{-1}$ air flow. Concentrations are expressed in moles per unit mass of liquid in the reactor $\left(\mathrm{mol} \cdot \mathrm{g}^{-1}\right)$. The symbols with error bars are the experimental results and the lines represent the kinetic model.

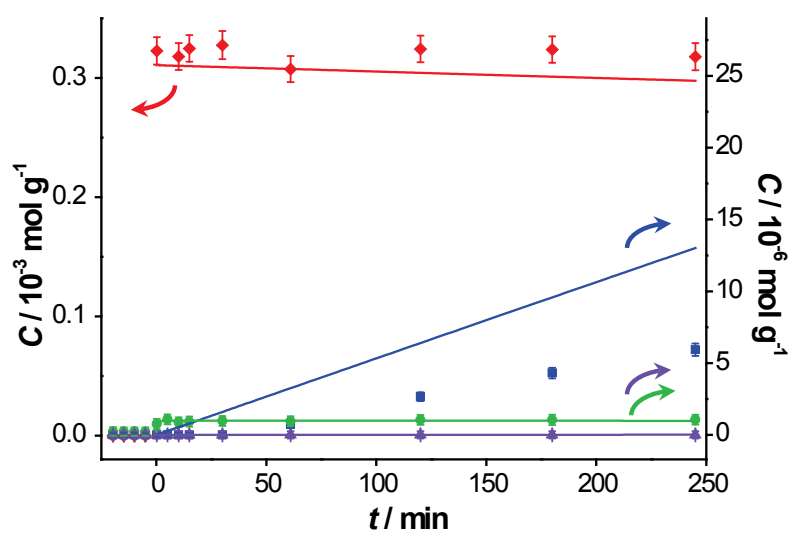

\subsection{Influence of a Base on Catalyst Deactivation}

Figure 5 shows the reaction mechanism, in basic conditions, of the oxidation of alcohol to aldehyde and the sequential oxidation to carboxylic acid [1,15,23-25]. $\mathrm{Au}^{*}$ indicates an active site on the gold surface. A dashed line represents a chemical interaction of a species with an adsorption site on the gold surface. Electron transfers corresponding to bond cleavage or formation are indicated by curved arrows. As indicated in Figure 5, reaction step a, the role of the base is to deprotonate the alcohol, thereby ensuring that the rate limiting step is the reaction on the gold surface, presumably the $\beta$-hydride elimination forming the aldehyde (step b yielding $\mathrm{R}-\mathrm{CH}=\mathrm{O}$ ) or the carboxylic acid (step $\mathrm{d}$ yielding R-COOH) [1,15,23-25]. However, basic conditions have also been reported to enhance the 
selectivity towards carboxylic acid, by favoring the conversion of aldehyde to the corresponding geminal diol $[1,15]$ as depicted by reaction step c (The diol is shown as $\mathrm{R}-\mathrm{CH}(\mathrm{OH}) \mathrm{O}^{-}$, partially deprotonated and adsorbed on $\left.\mathrm{Au}^{*}\right)$. In parallel, the gold site that carries the hydride $\left(\mathrm{Au}^{*}-\mathrm{H}^{-}\right)$is regenerated by adsorbed molecular oxygen $\left(\mathrm{Au}^{*}|||| \mathrm{O}_{2}\right)$ via a peroxyl intermediate (step e yielding $\left.\mathrm{Au}^{*}-\mathrm{O}-\mathrm{OH}\right)[1,15]$, or via dissociated oxygen from the catalyst support [25]. This also regenerates an $\mathrm{OH}^{-}$(steps f and g) [15] and closes the catalytic cycle as shown on the right-hand side of Figure 5. For stoichiometric reasons, it is clear that two hydrides species must react per $\mathrm{O}_{2}$ molecule. However, it is unclear whether the second hydride reacts after the O-O bond dissociation (step $\mathrm{f}$ ), or if the O-O bond dissociation is assisted by the second hydride (in the latter case, step $\mathrm{f}$ and $\mathrm{g}$ would be simultaneous). The question arises if the presence of a base has an influence on the catalyst stability.

Figure 5. Reaction mechanism of benzyl alcohol oxidation to benzaldehyde and sequential oxidation to benzoic acid over a gold catalyst, co-catalyzed by the base $\mathrm{HO}^{-}[1,15,23-25]$.

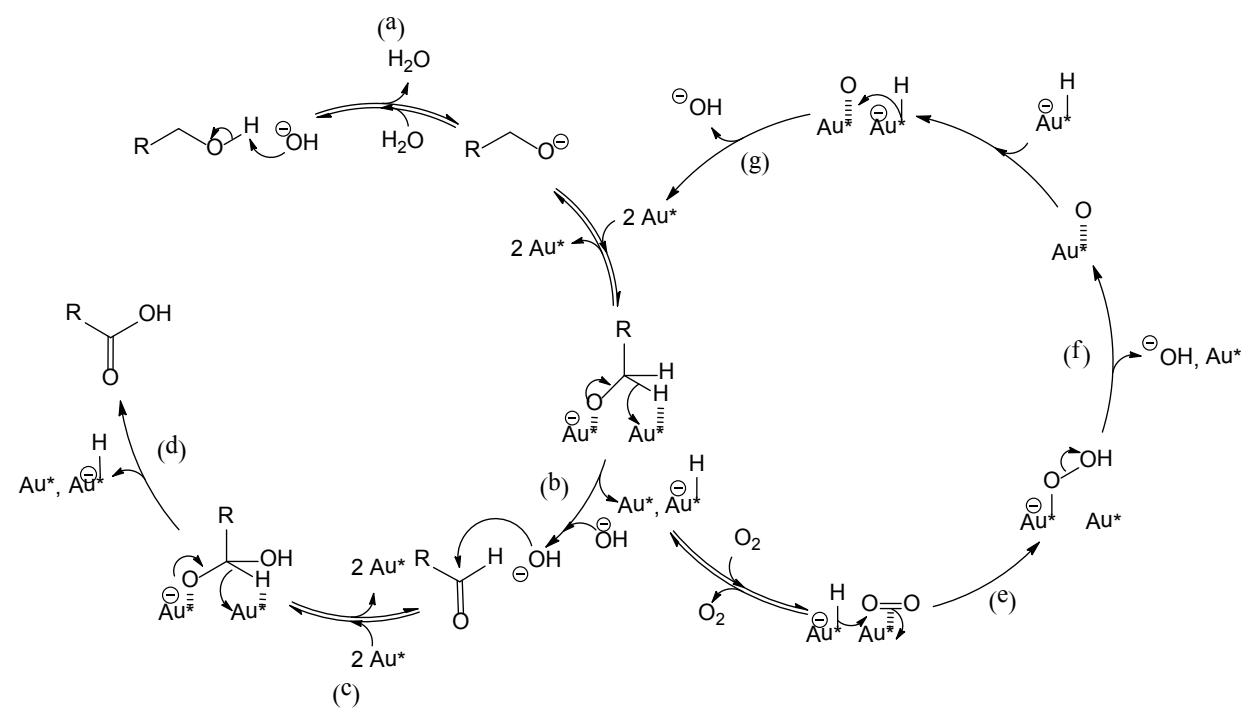

The catalytic reaction was carried out in the presence of two different bases: potassium carbonate $\left(p K_{\mathrm{b} 1}=3.68\right)$ and potassium fluoride $\left(p K_{\mathrm{b}}=10.8\right)$. Although the $p K_{\mathrm{b}}$ values (defined in aqueous environment) are not directly transferable to the aprotic solvent (toluene), and these bases hardly dissolve in toluene, the $p K_{\mathrm{b}}$ values still indicate the relative basicity of both bases used. The spent catalysts were also re-used. A significant loss of KF was observed during the recovery of the catalyst after the first test, which was compensated for by the addition of another $2.1 \mathrm{~g}$ of KF to the spent catalyst, resulting in an estimated total amount of KF present during the second experiment with the spent catalyst of about $3 \mathrm{~g}$. The concentration profiles of these experiments are presented in Figures 6 and 7 , respectively.

The results of the first run are similar to those for the base-free experiments, although a slight increase in the initial TOF, from 0.7 to $0.9 \mathrm{~s}^{-1}$, is observed (Table 1). Increased activity upon addition of a base has already been reported [1] and is probably due to the enhanced deprotonation of $\mathrm{BnOH}$. The conversion at $240 \mathrm{~min}$ is also higher: $78 \%$ compared with $63 \%$ in base-free conditions. The selectivity to $\mathrm{BnO}$ does not change significantly ( $93 \%$ when no base is present $v s .91 \%$ in the presence of potassium carbonate). However, it should be noted that more ester is formed in the presence of $\mathrm{K}_{2} \mathrm{CO}_{3}$ (at $240 \mathrm{~min}: 16 \mu \mathrm{mol} \cdot \mathrm{g}^{-1} \mathrm{compared}$ to $8 \mu \mathrm{mol} \cdot \mathrm{g}^{-1}$ in base free conditions), and the amount of 
$\mathrm{BnOOH}$ remains below detection limit. The most striking difference, when compared to base-free conditions, is the largely maintained activity when re-using the spent catalyst. The initial TOF is lower than that of the fresh catalyst $\left(0.4 \mathrm{~s}^{-1}\right.$ compared with $\left.0.9 \mathrm{~s}^{-1}\right)$, but the conversion at $240 \mathrm{~min}$ is comparable ( $72 \%$ compared with $78 \%$ ). This shows that the addition of a base to the reaction medium largely remediates the strong product inhibition observed under base-free conditions.

Figure 6. Catalyst performance in the presence of $\mathrm{K}_{2} \mathrm{CO}_{3}$. Concentration of ( $\downarrow$ ) benzyl alcohol, $(\boldsymbol{\nabla})$ benzaldehyde, $(\bullet)$ benzoic acid and $(\boldsymbol{\Delta})$ benzyl benzoate $v s$. reaction time for catalytic reaction over fresh AUROlite ${ }^{\mathrm{TM}}$ in the presence of $\mathrm{K}_{2} \mathrm{CO}_{3}$. (a) First run using fresh AUROlite $^{\mathrm{TM}}$ (b) second run using spent AUROlite ${ }^{\mathrm{TM}}$. Reaction conditions: $T=80^{\circ} \mathrm{C}, 0.8 \mathrm{~g}$ AUROlite $^{\mathrm{TM}}, 3.04 \mathrm{~g} \mathrm{~K}_{2} \mathrm{CO}_{3}, C_{\mathrm{BnOH}, t=0}=3.0 \times 10^{-4} \mathrm{~mol} \cdot \mathrm{g}^{-1}$, in $80 \mathrm{~mL}$ of toluene, $200 \mathrm{~mL} \cdot \mathrm{min}^{-1}$ air flow. Concentrations are expressed in moles per unit mass of liquid in the reactor $\left(\mathrm{mol} \cdot \mathrm{g}^{-1}\right)$. The symbols with error bars are the experimental results and the lines represent the kinetic model.
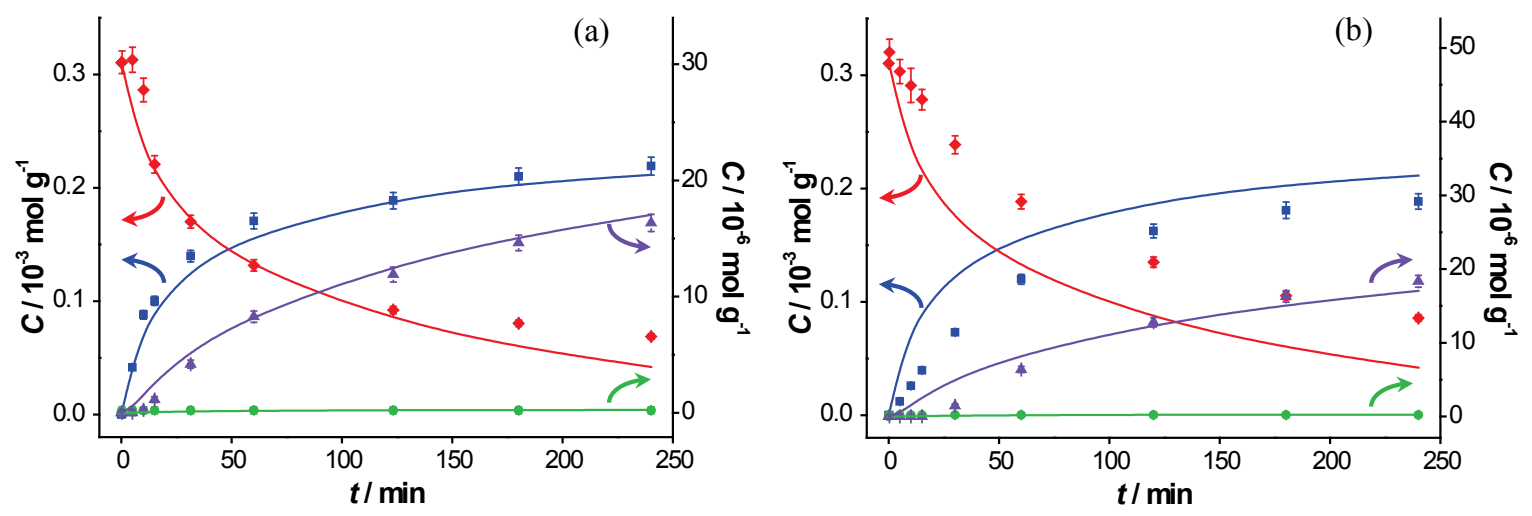

Figure 7. Catalyst performance in the presence of KF. Concentration of $(\diamond)$ benzyl alcohol, $(\boldsymbol{\nabla})$ benzaldehyde, $(\bullet)$ benzoic acid and $(\boldsymbol{\Delta})$ benzyl benzoate $v s$. reaction time for catalytic reaction over fresh AUROlite ${ }^{\mathrm{TM}}$ in the presence of KF. (a) First run using fresh AUROlite ${ }^{\mathrm{TM}}$ and $2.1 \mathrm{~g} \mathrm{KF}$ (b) second run using spent AUROlite ${ }^{\mathrm{TM}}$ and $\sim 3 \mathrm{~g}$ KF. Reaction conditions: $T=80{ }^{\circ} \mathrm{C}, 0.8 \mathrm{~g}$ AUROlite ${ }^{\mathrm{TM}}, C_{\mathrm{BnOH}, t=0}=3.0 \times 10^{-4} \mathrm{~mol} \cdot \mathrm{g}^{-1}$, in $80 \mathrm{~mL}$ of toluene, $200 \mathrm{~mL} \cdot \mathrm{min}^{-1}$ air flow. Concentrations are expressed in moles per unit mass of liquid in the reactor $\left(\mathrm{mol} \cdot \mathrm{g}^{-1}\right)$. The symbols with error bars are the experimental results and the lines represent the kinetic model.
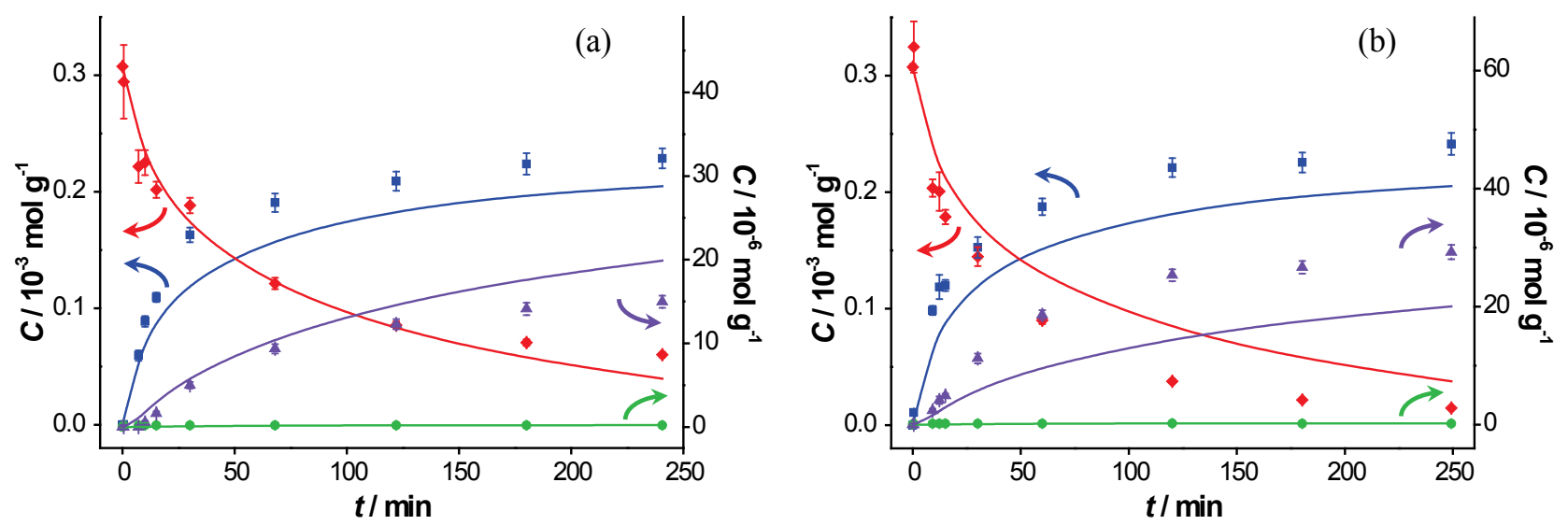
When $\mathrm{K}_{2} \mathrm{CO}_{3}$ is replaced by an equimolar amount of $\mathrm{KF}$, the results are similar. TOF is slightly lower $\left(0.6 \mathrm{~s}^{-1}\right)$ although the difference is within the measurement error. The conversion is $81 \%$ after 240 min when $\mathrm{KF}$ is used, and $78 \%$ when $\mathrm{K}_{2} \mathrm{CO}_{3}$ is used (Table 1). Apparently, the strength of the base does not affect the activity of the fresh catalyst. Upon re-using the spent catalyst however, a higher initial reaction rate is observed $\left(1.0 \mathrm{~s}^{-1}\right)$ and the final conversion even reaches $95 \%$. This increase is attributed to the additional potassium fluoride added. The preserved catalytic activity proves that no other deactivation mechanism than product inhibition (e.g., sintering or poisoning) is taking place. It is clear that the bases largely neutralize the acid responsible for product inhibition. As this alleviation of the inhibition is always accompanied by an increase of selectivity towards BnOOBn, apparently ester formation is faster in the presence of a base. However, direct esterification of the carboxylic acid with the alcohol catalyzed by a base is mechanistically not likely. After deprotonation of the $\mathrm{BnOOH}$ by a base, nucleophilic attack of the alcohol $\left(\mathrm{R}-\mathrm{CH}_{2}-\mathrm{OH}\right)$ on the functional carbon of carboxylate anion ( $\mathrm{R}-\mathrm{COO}^{-}$) is highly unlikely as this would imply that a nucleophile (also seen as a Lewis base) would have to react with an electron rich species. This is illustrated in Figure 8 (steps $\mathrm{d}$ and e). The classic acid-catalyzed esterification between carboxylic acid and alcohol is depicted on the left hand-side of Figure 8 for comparison. It shows that under acidic conditions, the functional carbon becomes positively charged (Figure 8 step a, yielding $\mathrm{R}-\mathrm{C}(\mathrm{OH})_{2}{ }^{+}$) and thus more prone to nucleophilic attack. Another pathway involving base-catalyzed ester formation from an alcohol and an aldehyde has been suggested by Rodríguez-Reyes et al. [19]. This pathway is illustrated in Figure 9, and can explain why in our system a higher ester production is observed under basic conditions.

Figure 8. Reaction mechanism of acid catalyzed esterification of carboxylic acid and alcohol. (a) protonation of carbonyl oxygen yielding an electrophilic carbocation; (b) nucleophilic attack of the alcohol and (c) dehydration yielding the corresponding ester. (d) deprotonation of the carboxylic acid by a base yielding a carboxylate anion; (e) the nucleophilic attack of the alcohol is then greatly disfavored.

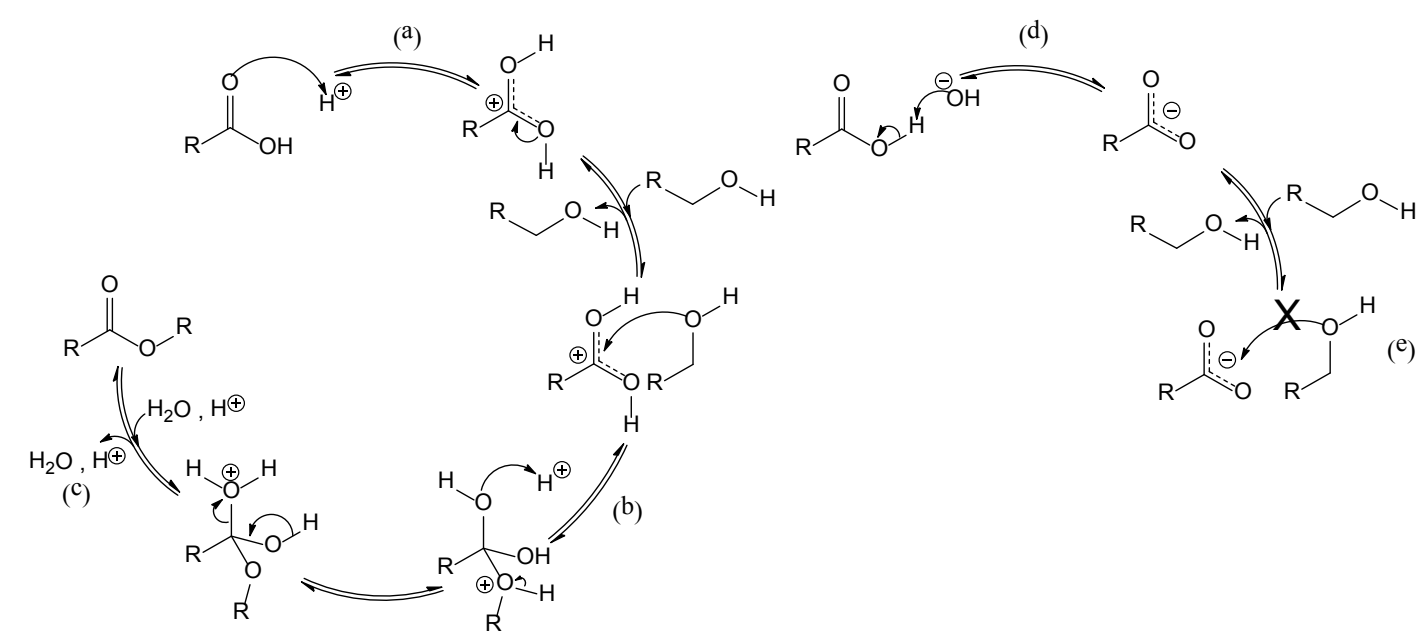


Figure 9. Reaction mechanism of base-catalyzed ester formation from alcohol and aldehyde, adapted from [19]. (a) alcohol deprotonation, (b) nucleophilic attack of alcoholate on carbonyl, followed by (c) $\beta$-hydride elimination yields the corresponding ester. The rest of the catalytic cycle consists of the oxidation of the hydride left on the gold surface by molecular oxygen, which also regenerates the base as depicted in Figure 5 (steps f and g).

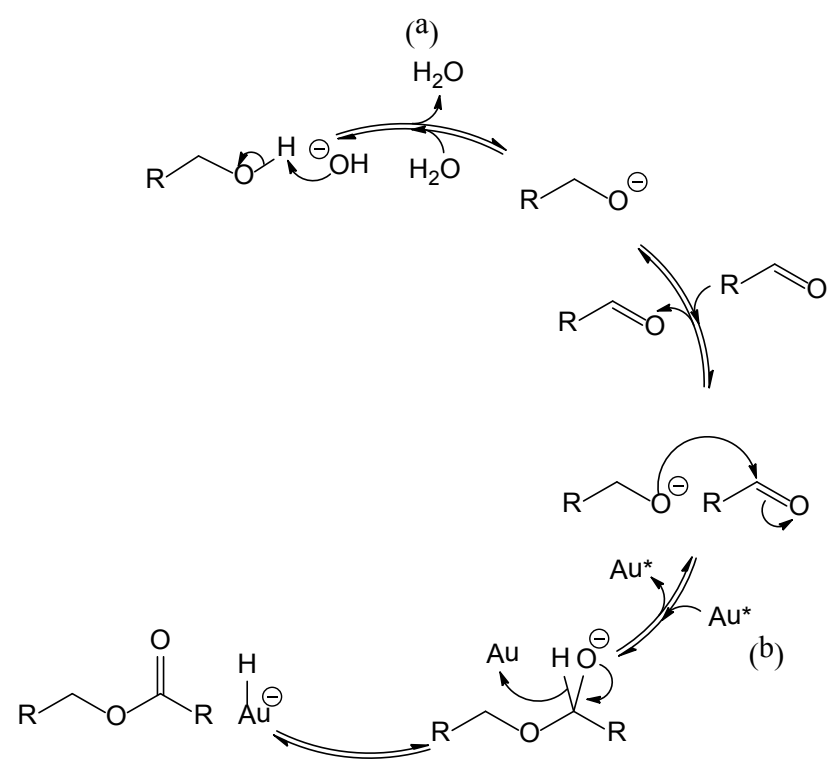

(c)

To further elucidate the role of the base on product inhibition, an experiment was performed with potassium carbonate and pre-addition of $\mathrm{BnOOH}$. The concentration profiles are shown in Figure 10 and are directly comparable with the ones shown in Figure $6 \mathrm{a}$ where $\mathrm{K}_{2} \mathrm{CO}_{3}$ was present but no inhibitor was pre-added, and with Figure 4 where no base was present but $\mathrm{BnOOH}$ was pre-added.

In comparison with Figure 6a where no $\mathrm{BnOOH}$ was added, the initial TOF is lower: $0.2 \mathrm{~s}^{-1}$ (Table 1). The conversion after $240 \mathrm{~min}$ is $61 \%$ and the selectivity to $\mathrm{BnO}$ is $92 \%$. When compared with the results in Figure 4 (no carbonate added), we can conclude that even though inhibition is still observed, the presence of potassium carbonate greatly reduces it.

Based on our interpretation, the presence of a base results in (partial) neutralization of the $\mathrm{BnOOH}$, thereby alleviating inhibition. In parallel, basic conditions also enhance the subsequent ester formation depicted in Figure 9, leading to more ester production and decreasing aldehyde selectivity. An effect of the amount of potassium on the inhibition is also suspected based on Figure $7 \mathrm{a}, \mathrm{b}$, but this has not been further quantified. 
Figure 10. Catalyst performance in the presence of $\mathrm{K}_{2} \mathrm{CO}_{3}$ after pre-addition of benzoic acid. Concentration of $(\diamond)$ benzyl alcohol, $(\square)$ benzaldehyde, $(\bullet)$ benzoic acid and $(\boldsymbol{\Delta})$ benzyl benzoate vs. reaction time for catalytic reaction over fresh AUROlite ${ }^{\mathrm{TM}}$ where benzoic acid was introduced prior to the beginning of the reaction. Reaction conditions: $T$ $=80{ }^{\circ} \mathrm{C}, 0.8 \mathrm{~g}$ AUROlite $^{\mathrm{TM}}, 3.04 \mathrm{~g} \mathrm{~K}_{2} \mathrm{CO}_{3}, C_{\mathrm{BnOH}, t=0}=3.0 \times 10^{-4} \mathrm{~mol} \cdot \mathrm{g}^{-1}, C_{\mathrm{BnOOH}, t<0}=4.1$ $\times 10^{-6} \mathrm{~mol} \cdot \mathrm{g}^{-1}$, in $80 \mathrm{~mL}$ of toluene, $200 \mathrm{~mL} \cdot \mathrm{min}^{-1}$ air flow. Concentrations are expressed in moles per unit mass of liquid in the reactor $\left(\mathrm{mol} \cdot \mathrm{g}^{-1}\right)$. The symbols with error bars are the experimental results and the lines represent the kinetic model.

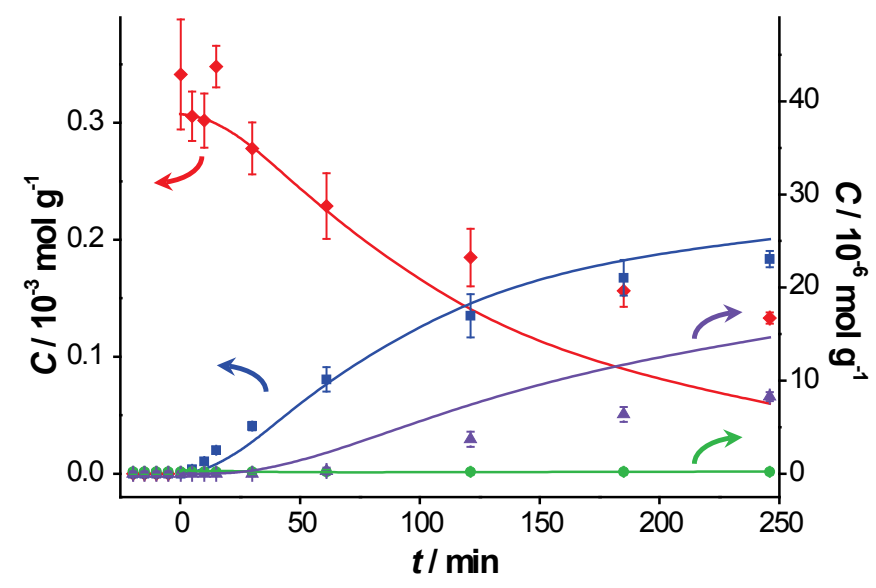

\subsection{Influence of Water on Catalyst Deactivation}

Water was already recognized to be crucial for Au-catalyzed gas phase $\mathrm{CO}$ oxidation by Daté et al. [26], who demonstrated its great beneficial role. The mechanism was later proposed by Daniells et al. [27]. In many of the reaction mechanisms discussed above, water plays a role. It is produced in an amount equimolar to $\mathrm{BnO}$ (see Figures 1a and 5a). The mechanism of the oxidation of aldehyde to carboxylic acid involves a base-catalyzed hydration of aldehyde to geminal diol. Water is also a byproduct of the equilibrium-limited esterification. Yang et al. [28] studied the influence of different water contents on the kinetics of oxidation and determined that water has a promoting effect. They observed higher conversions of $\mathrm{BnOH}$ and higher selectivities to $\mathrm{BnO}$ when an optimal amount of water was used. More recently, Chang and coworkers [29] conducted a computational study to better understand this effect on methanol dehydrogenation/oxidation. They concluded that the promoting effect originates from a facilitated peroxyl formation from $\mathrm{O}_{2}$ by transfer of hydrogen from the water itself or from the alcohol via the water, where hydrogen bonds are reported to play a key role in this mechanism. Therefore, water could play a role in the deactivation of the catalyst in the present study. With this in mind, the reaction was carried out in the presence of the small amount of water that adheres to the catalyst after immersion in water and filtration. The mass difference before and after this treatment indicates about $0.5 \mathrm{~g}$ of water per gram of catalyst, which corresponds to around $550 \mathrm{~mol}$ of water per mol of gold. The results of this experiment are presented in Figure 11. 
Figure 11. Catalyst performance in the presence of $\mathrm{K}_{2} \mathrm{CO}_{3}$ and a small amount of water. Concentration profiles of $(\diamond)$ benzyl alcohol, $(\boldsymbol{\bullet})$ benzaldehyde, $(\bullet)$ benzoic acid and $(\boldsymbol{\Delta})$ benzyl benzoate $v$ s. reaction time for catalytic reaction over fresh AUROlite ${ }^{\mathrm{TM}}$ in the presence of water. Reaction conditions: $T=80{ }^{\circ} \mathrm{C}, 0.8 \mathrm{~g}^{\text {AUROlite }}{ }^{\mathrm{TM}}, 3.04 \mathrm{~g} \mathrm{~K}_{2} \mathrm{CO}_{3}, \sim 0.4 \mathrm{~g} \mathrm{H}_{2} \mathrm{O}$, $C_{\mathrm{BnOH}, t=0}=3.0 \times 10^{-4} \mathrm{~mol} \cdot \mathrm{g}^{-1}$, in $80 \mathrm{~mL}$ of toluene, $200 \mathrm{~mL} \cdot \mathrm{min}^{-1}$ air flow. Concentrations are expressed in moles per unit mass of liquid in the reactor $\left(\mathrm{mol} \cdot \mathrm{g}^{-1}\right)$. The symbols with error bars are the experimental results and the lines represent the kinetic model.

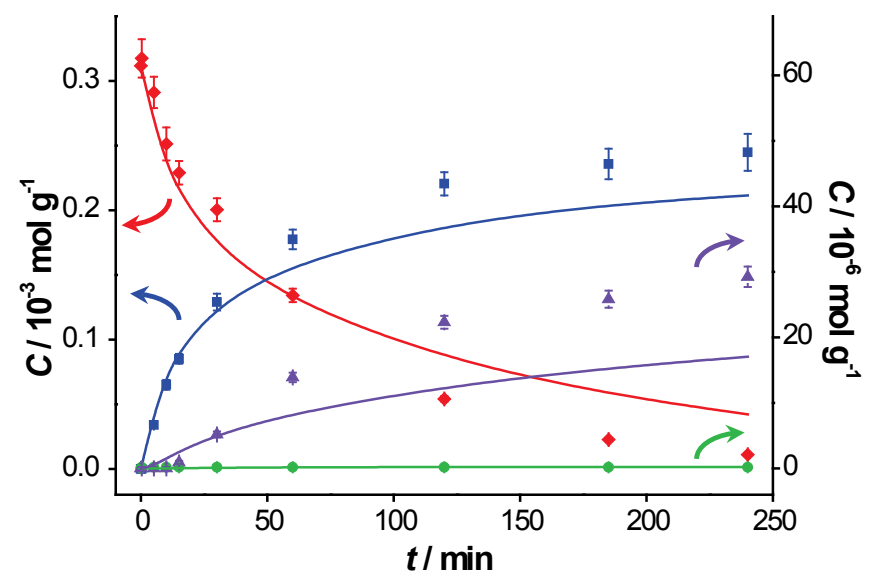

Compared with the dry conditions of Figure 6a the initial TOFs are equal within the experimental error, being $0.8 \mathrm{~s}^{-1}$ in moist conditions and $0.9 \mathrm{~s}^{-1}$ in dry conditions. We do not observe the kinetic effect of water found by Yang et al., but in the presence of water our catalyst does not deactivate and the final conversion is close to $100 \%$. The water thus positively influences the catalyst stability. A possible explanation could be that water interacts with the inhibiting product, thereby diminishing its interaction with the catalyst. However, since potassium carbonate was also present in the reactor, a synergistic effect of base and water cannot be excluded. To address this question, the deactivated catalyst obtained after the experiment of Figure $2 b$ (where no base was present) was tested again in the presence of water and without the addition of any base. Concentration profiles of this experiment are displayed in Figure 12.

Clearly, catalytic activity could not be recovered by this treatment. Thus, water alone does not remove the species responsible for deactivation, and the beneficial influence of water observed in Figure 11 is due to a synergistic effect with the potassium carbonate, e.g., by an enhanced dissolution of the inorganic base. It should also be noted that adding more water than used in these experiments provoked phase separation in which the catalyst agglomerated in the water phase, thereby eliminating the dispersion of the catalyst powder in the organic phase and causing the reaction to proceed in a mass-transport limited regime. 
Figure 12. Catalyst performance of the water-washed spent catalyst in base-free conditions from Figure 2 in the presence of water. Concentration of ( $\$$ ) benzyl alcohol, ( $\square$ ) benzaldehyde, $(\bullet)$ benzoic acid and $(\boldsymbol{\Delta})$ benzyl benzoate $v$ s. reaction time for catalytic reaction spent AUROlite ${ }^{\mathrm{TM}}$ in the presence of water. Reaction conditions: $T=80{ }^{\circ} \mathrm{C}, 0.8 \mathrm{~g}$ AUROlite $^{\mathrm{TM}}, \sim 1 \mathrm{~g} \mathrm{H}_{2} \mathrm{O}, C_{\mathrm{BnOH}, t=0}=3.0 \times 10^{-4} \mathrm{~mol} \cdot \mathrm{g}^{-1}$, in $80 \mathrm{~mL}$ of toluene, $200 \mathrm{~mL} \cdot \mathrm{min}^{-1}$ air flow. Concentrations are expressed in moles per unit mass of liquid in the reactor $\left(\mathrm{mol} \cdot \mathrm{g}^{-1}\right)$. The symbols with error bars are the experimental results and the lines represent the kinetic model.

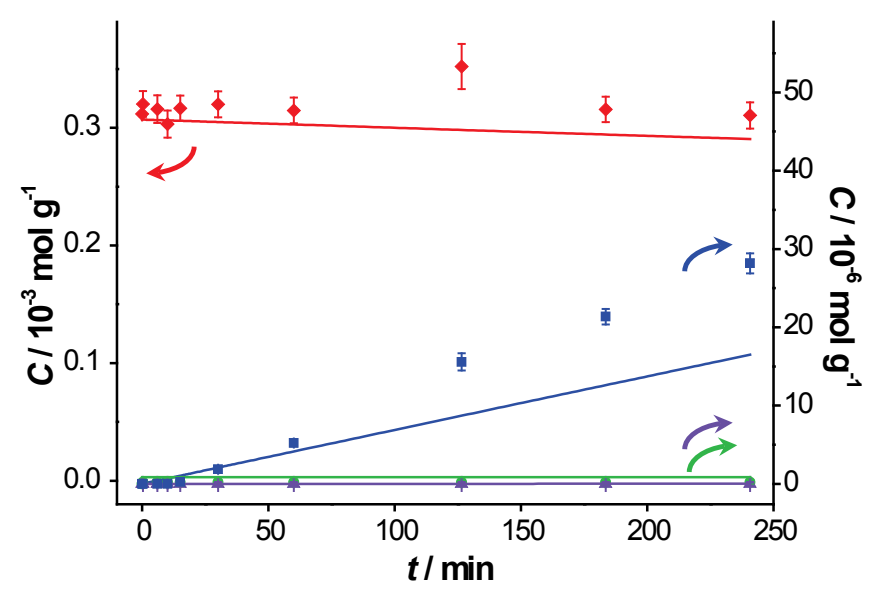

In order to further assess which hypothesis holds, the spent catalyst was analyzed by DRIFTS before and after washing in boiling water for $12 \mathrm{~h}$ (Figure 13). The fresh catalyst barely shows any features. In contrast, both the spent catalyst and the spent catalyst after boiling in water show clear absorption features. The catalyst tested in the presence of KF, which did not deactivate after two runs, exhibited different features. Identification of the species on the surface of the catalysts was based on reference spectra recorded of the compounds present in the reactor adsorbed on alumina. The band at $1200 \mathrm{~cm}^{-1}$ is attributed to $\mathrm{C}_{\text {arom }}-\mathrm{CHO}$ or $\mathrm{C}_{\text {arom }}-\mathrm{CH}_{2} \mathrm{OH}$ stretching vibrations [30] and originates only from $\mathrm{BnOH}$ and $\mathrm{BnO}$. Interestingly, this band is only present for the catalyst tested with $\mathrm{KF}$. A small absorption band at $1390 \mathrm{~cm}^{-1}$ is seen in practically all cases and corresponds to the bending vibration of $\mathrm{O}-\mathrm{H}$ bonds; thus, it cannot be used to differentiate the components of interest. The sharp absorption at $1450 \mathrm{~cm}^{-1}$ is due to in-plane bending vibrations of protons at a primary alcohol carbon and is specific to $\mathrm{BnOH}$. Unfortunately, this band is often masked by a broader one due to other $\mathrm{O}-\mathrm{H}$ vibrations at the same wavenumber. Absorptions between 1500 and $1600 \mathrm{~cm}^{-1}$ are attributed to $\mathrm{C}_{\mathrm{sp} 2}=\mathrm{C}_{\mathrm{sp} 2}$ stretching vibrations present in all the compounds of interest. The broad band at $1710 \mathrm{~cm}^{-1}$ is specific to benzaldehydes and is due to $\pi$-conjugation of bonds throughout the entire molecule. Again, this characteristic feature is only present for the catalyst tested with KF. A smaller feature is also observed for $\mathrm{BnOOH}$ for the same reasons, but the carboxyl moiety seems to alter it drastically. The bending mode of water, which should appear at around $1600-1800 \mathrm{~cm}^{-1}$, is hardly visible due to the pre-treatment of the samples at $473 \mathrm{~K}$. Some features are also observed at higher wavenumbers. The small bands centered at around $2740 \mathrm{~cm}^{-1}$ and $2820 \mathrm{~cm}^{-1}$ arise from wagging and stretching vibrations respectively of the $\mathrm{BnO}$ carbonyl proton, but these bands are not detected on any of the spent catalysts. The symmetric and anti-symmetric stretching vibrations of primary alcohol methylene group protons give rise 
to absorptions at 2870 and $2930 \mathrm{~cm}^{-1}$, respectively. The three bands between 3030 and $3090 \mathrm{~cm}^{-1}$ are assigned to $\mathrm{C}_{\mathrm{sp} 2}-\mathrm{H}$ vibrations, which stem from any aromatic compound in the reaction medium.

Figure 13. DRIFT spectra of (a) fresh AUROlite ${ }^{\mathrm{TM}}$ catalyst; (b) used with $\mathrm{K}_{2} \mathrm{CO}_{3}$; (c) used with $\mathrm{K}_{2} \mathrm{CO}_{3}$ and washed in boiling water; (d) used with $\mathrm{KF}$, (e)-(i) reference compounds adsorbed on alumina. Catalyst samples were pretreated under He at $473 \mathrm{~K}$ before recording.

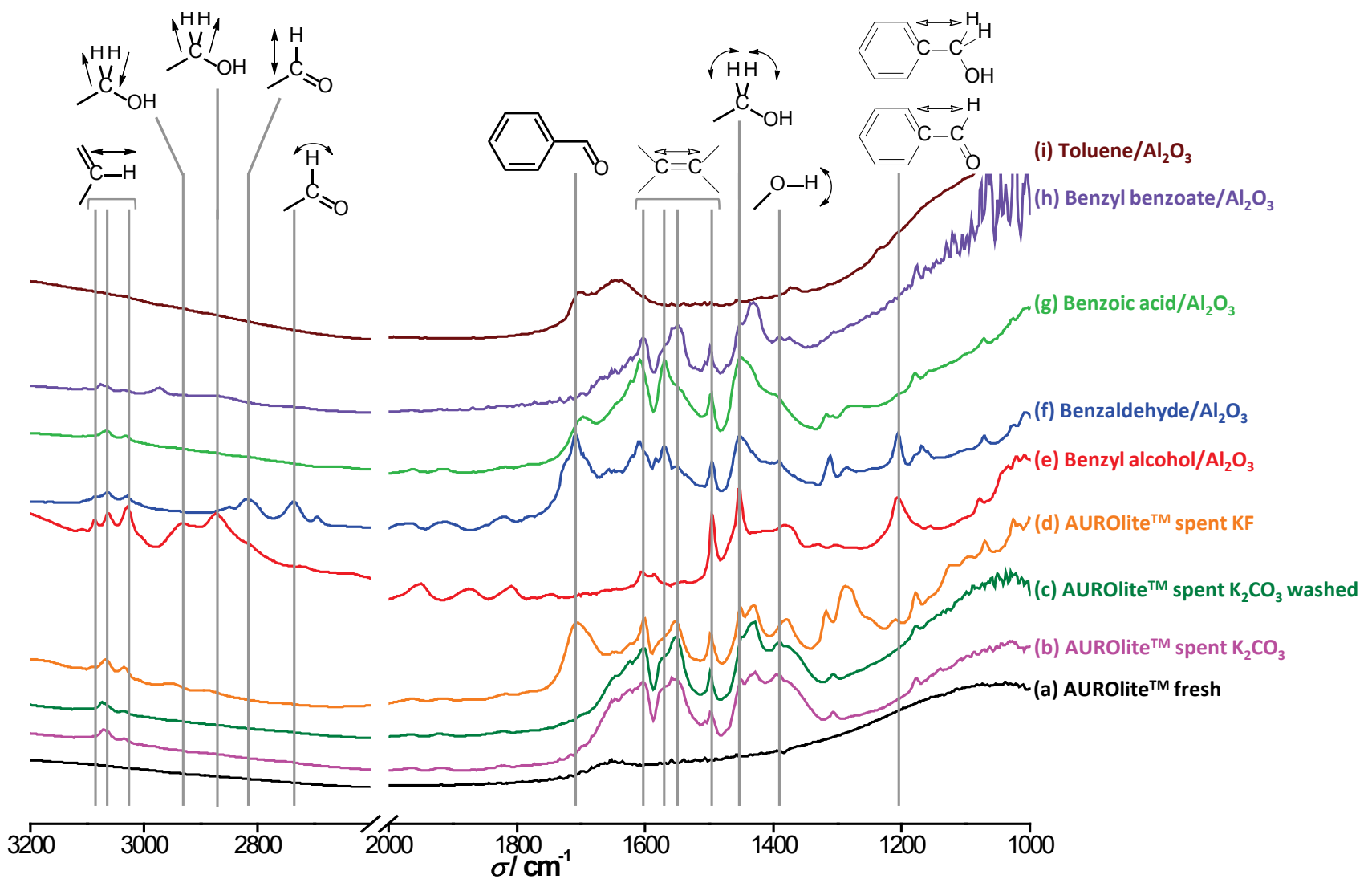

Figure 13 clearly demonstrates that water does not visibly wash off the species involved in the reaction from the catalyst surface. Even after $12 \mathrm{~h}$ in boiling water, the intensities of the absorption bands corresponding to aromatic species and oxygenated aromatic species do not show any sign of decrease. Therefore, combined with the results of Figure 12, the hypothesis that water remediates the product inhibition by enhancing desorption of the inhibiting product is refuted. The absorption features on the catalyst tested in the presence of $\mathrm{K}_{2} \mathrm{CO}_{3}$ are very similar to those of $\mathrm{BnOOH}$ and $\mathrm{BnOOBn}$, although the observed bands are not specific to these compounds. In contrast, the catalyst tested in the presence of KF shows absorption features similar to those of $\mathrm{BnO}$, in particular the characteristic band at $1710 \mathrm{~cm}^{-1}$. Since this catalyst did not deactivate whereas the catalyst tested with $\mathrm{K}_{2} \mathrm{CO}_{3}$ showed some deactivation, the attribution of the inhibitor being $\mathrm{BnOOH}$ or one of its products is supported. However, in view of the low degree of deactivation shown by the catalyst tested in the presence of $\mathrm{K}_{2} \mathrm{CO}_{3}$, a signal corresponding to $\mathrm{BnO}$ would be expected. It remains unclear why $\mathrm{BnO}$ seems to be absent from this catalyst surface despite the fact that $\mathrm{KF}$ and $\mathrm{K}_{2} \mathrm{CO}_{3}$ have similar beneficial effects. 


\subsection{Kinetic Modeling}

Since our experiments show that the $\mathrm{BnOOH}$ concentration in solution is very low at all times and that the ester formation increases in the presence of a base, it is assumed that the esterification runs entirely through the reaction of $\mathrm{BnO}$ with $\mathrm{BnOH}$ by $\mathrm{H}$ abstraction. The reactions involved in the model are:

$$
\begin{aligned}
& \mathrm{C}_{6} \mathrm{H}_{5} \mathrm{CH}_{2} \mathrm{OH}+\frac{1}{2} \mathrm{O}_{2} \longrightarrow \mathrm{C}_{6} \mathrm{H}_{5} \mathrm{CHO}+\mathrm{H}_{2} \mathrm{O} \\
& \mathrm{C}_{6} \mathrm{H}_{5} \mathrm{CHO}+\frac{1}{2} \mathrm{O}_{2} \longrightarrow \mathrm{C}_{6} \mathrm{H}_{5} \mathrm{COOH} \\
& \mathrm{C}_{6} \mathrm{H}_{5} \mathrm{CHO}+\mathrm{C}_{6} \mathrm{H}_{5} \mathrm{CH}_{2} \mathrm{OH}+\frac{1}{2} \mathrm{O}_{2} \longrightarrow \mathrm{C}_{6} \mathrm{H}_{5} \mathrm{COOCH} \mathrm{C}_{6} \mathrm{H}_{5}+\mathrm{H}_{2} \mathrm{O}
\end{aligned}
$$

The reaction model is accordingly assumed to consist of the set of surface reactions shown in the following set of equations, in which $*$ stands for a catalytic oxidation site:

$$
\begin{aligned}
& \text { BnOH adsorption } \quad \mathrm{C}_{6} \mathrm{H}_{5} \mathrm{CH}_{2} \mathrm{OH}+* \rightleftharpoons \mathrm{C}_{6} \mathrm{H}_{5} \mathrm{CH}_{2} \mathrm{OH} * \\
& \text { BnO adsorption } \quad \mathrm{C}_{6} \mathrm{H}_{5} \mathrm{CHO}+* \rightleftharpoons \mathrm{C}_{6} \mathrm{H}_{5} \mathrm{CHO} * \\
& \text { BnOH oxidation } \quad \mathrm{C}_{6} \mathrm{H}_{5} \mathrm{CH}_{2} \mathrm{OH} *+* \longrightarrow \mathrm{C}_{6} \mathrm{H}_{5} \mathrm{CHOH} *+\mathrm{H} * \\
& \mathrm{H} * \frac{\frac{1}{4} \mathrm{O}_{2}}{\text { fast }} *+\frac{1}{2} \mathrm{H}_{2} \mathrm{O}
\end{aligned}
$$

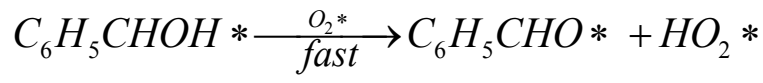

$$
\begin{aligned}
& \mathrm{HO}_{2} * \underset{\text { fast }}{\longrightarrow} \frac{1}{2} \mathrm{H}_{2} \mathrm{O}+\frac{3}{4} \mathrm{O}_{2} \\
& \text { BnO hydration } \quad \mathrm{C}_{6} \mathrm{H}_{5} \mathrm{CHO} * \frac{\mathrm{H}_{2} \mathrm{O}}{\underset{-\mathrm{H}_{2} \mathrm{O}}{\rightleftharpoons}} \mathrm{C}_{6} \mathrm{H}_{5} \mathrm{CH}(\mathrm{OH})_{2} \text { * } \\
& \text { BnO oxidation } \quad \mathrm{C}_{6} \mathrm{H}_{5} \mathrm{CH}(\mathrm{OH})_{2}{ }^{*}+* \longrightarrow \mathrm{C}_{6} \mathrm{H}_{5} \mathrm{CHO}(\mathrm{OH}) *+\mathrm{H} * \\
& \mathrm{H} * \frac{\frac{1}{4} \mathrm{O}_{2}}{\text { fast }} *+\frac{1}{2} \mathrm{H}_{2} \mathrm{O}
\end{aligned}
$$

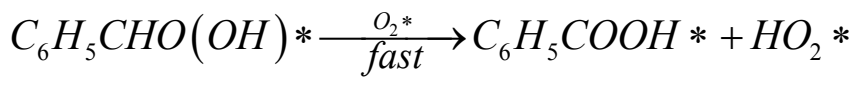

$$
\begin{aligned}
& \mathrm{HO}_{2} * \underset{\text { fast }}{\longrightarrow} \frac{1}{2} \mathrm{H}_{2} \mathrm{O}+\frac{3}{4} \mathrm{O}_{2} \\
& 2 \mathrm{H} * \underset{\text { fast }}{\stackrel{\frac{1}{2} \mathrm{O}_{2}}{\longrightarrow}} *+\mathrm{H}_{2} \mathrm{O}
\end{aligned}
$$

It is assumed that all three surface oxidation reactions are irreversible. These reactions require two adjacent sites, one for the adsorbed species originating from the $\mathrm{BnOH}$ or $\mathrm{BnO}$ and one empty site that was regenerated by the oxygen or, for the esterification, adjacently adsorbed $\mathrm{BnOH}$ or $\mathrm{BnO}$. It is also 
assumed that the hydride species, $\mathrm{H}^{*}$, and the peroxy species. $\mathrm{HO}_{2}{ }^{*}$, are quickly removed in the excess of oxygen present, leading to the assumption that the occupancy of both species is always very low. Adsorption of water and oxygen is assumed not to inhibit the reaction. The surface reactions are described by the surface species reaction rates shown in the following equations:

$$
\begin{aligned}
& \mathrm{BnOH} \text { adsorption } \quad r_{\mathrm{BnOH}}=k_{\mathrm{BnOH}} C_{\mathrm{BnOH}} N_{T} \theta_{*}-k_{-\mathrm{BnOH}} N_{T} \theta_{\mathrm{BnOH} *} \\
& \text { BnO adsorption } \quad r_{B n O}=k_{B n O} C_{B n O} N_{T} \theta_{*}-k_{-B n O} N_{T} \theta_{B n O *} \\
& \mathrm{BnOOH} \text { adsorption } \quad r_{\mathrm{BnOOH}}=k_{\mathrm{BnOOH}} C_{\mathrm{BnOOH}} N_{T} \theta_{*}-k_{-\mathrm{BnOOH}} N_{T} \theta_{\mathrm{BnOOH} *} \\
& \text { BnOOBn adsorption } \quad r_{B n O O B n}=k_{B n O O B n} C_{B n O O B n} N_{T} \theta_{*}-k_{-B n O O B n} N_{T} \theta_{B n O O B n *} \\
& \text { BnOH oxidation } \quad r_{1}=k_{1}^{\prime} N_{T} \theta_{B n O H *} \theta_{*} s \\
& \text { BnO oxidation } \quad r_{2}=k_{2}^{\prime} N_{T} \theta_{B n O *} \theta_{*} S \\
& \text { BnOOBn formation } \quad r_{3}=k_{3}^{\prime} N_{T} \theta_{B n O *} \theta_{B n O H *} S
\end{aligned}
$$

The hydration of $\mathrm{BnO}$ followed by the sequential oxidation of the diol species has been lumped here into a single step (17), as the equilibrium constant of the reversible hydration will be highly correlated with the rate constant of the oxidation step.

In general, adsorption reactions are at quasi-equilibrium, while the surface reactions are rate-limiting steps. This allows expression of the surface coverages as functions of the concentrations and the adsorption constants:

$$
\begin{array}{ll}
\text { BnOH adsorption } & \theta_{B n O H *}=K_{B n O H} C_{B n O H} \theta_{*} \text { with } K_{B n O H}=k_{B n O H} / k_{-B n O H} \\
\text { BnO adsorption } & \theta_{B n O *}=K_{B n O} C_{B n O} \theta_{*} \text { with } K_{B n O}=k_{B n O} / k_{-B n O} \\
\text { BnOOH adsorption } & \theta_{B n O O H *}=K_{B n O O H} C_{B n O O H} \theta_{*} \text { with } K_{B n O O H}=k_{B n O O H} / k_{-B n O O H} \\
\text { BnOOBn adsorption } & \theta_{B n O O B n *}=K_{B n O O B n} C_{B n O O B n} \theta_{*} \text { with } K_{B n O O B n}=k_{B n O O B n} / k_{-B n O O B n}
\end{array}
$$

Where: $K_{i}=$ adsorption constant of compound $i$ on a gold active site $\left(\mathrm{g} \cdot \mathrm{mol}^{-1}\right)$

After substitution of all the surface coverage expressions in the site balance:

$$
\begin{gathered}
\theta_{\mathrm{BnOH} *}+\theta_{\mathrm{BnO} *}+\theta_{\mathrm{BnOOH} *}+\theta_{\mathrm{BnOOBn} *}+\theta_{*}=1 \\
\theta_{*}=\frac{1}{\left(1+K_{\mathrm{BnOH}} C_{\mathrm{BnOH}}+K_{B n O} C_{B n O}+K_{B n O O H} C_{B n O O H}+K_{B n O O B n} C_{B n O O B n}\right)}
\end{gathered}
$$


The kinetic parameter estimation based on the full model showed that not all adsorption constants could be estimated properly due to a too weak sensitivity. It appeared that only the adsorption term of the most polar species present, $\mathrm{BnOOH}$, was significant allowing the estimation of its adsorption constant and neglecting the adsorption terms of the $\mathrm{BnOH}$, the $\mathrm{BnO}$ and the $\mathrm{BnOOBn}$. Since it was experimentally observed that the presence of a base, i.e., $\mathrm{K}_{2} \mathrm{CO}_{3}$ or $\mathrm{KF}$, results in significant ester formation, it was assumed that this reaction is base-catalyzed. Since hardly any ester is formed in absence of base, it is concluded that the condensation reaction of $\mathrm{BnOOH}$ and $\mathrm{BnOH}$ does not occur to any significant extent.

By elimination of the coverages of the surface species, the following reaction rate expressions are obtained:

$$
\begin{array}{ll}
r_{1}=\frac{k_{1}}{\left(1+K_{B n O O H} C_{B n O O H}\right)^{2}} C_{B n O H} & \text { With: } k_{1}=k_{1}^{\prime} K_{B n O H} N_{T} S \\
r_{2}=\frac{k_{2}}{\left(1+K_{B n O O H} C_{B n O O H}\right)^{2}} C_{B n O} & \text { With: } k_{2}=k_{2}^{\prime} K_{B n O} N_{T} S \\
r_{3}=\frac{S_{\text {base }} k_{3}}{\left(1+K_{B n O O H} C_{B n O O H}\right)^{2}} C_{B n O} C_{B n O H} & \text { With: } k_{3}=k_{3}^{\prime} K_{B n O} K_{B n O H} N_{T} S
\end{array}
$$

Where: $\quad r_{i}=$ reaction rate $\left(\mathrm{mol} \cdot \mathrm{kg}_{\mathrm{cat}}{ }^{-1} \cdot \mathrm{s}^{-1}\right)$

$k_{i}=$ lumped rate constant (unit according to equations)

$C_{i}=$ concentration $\left(\mathrm{mol} \cdot \mathrm{g}^{-1}\right)$

$S_{\text {base }}=$ base strength $\left(\mathrm{K}_{2} \mathrm{CO}_{3}\right.$ or KF) (-)

In the two catalytic experiments in which $\mathrm{BnOOH}$ was added prior to the $\mathrm{BnOH}$ (Figures 4 and 10), it was observed that the catalyst support $\mathrm{Al}_{2} \mathrm{O}_{3}$ adsorbs $\mathrm{BnOOH}$ more strongly than $\mathrm{BnOH}$. In the first experiment (Figure 4), it was observed that the molar quantity of $\mathrm{BnOOH}$ in the liquid was much lower $(16 \mu \mathrm{mol})$ than that originally added $(780 \mu \mathrm{mol})$. The amount of $\mathrm{BnOOH}$ in solution increased only slightly (to $74 \mu \mathrm{mol}$ ) after subsequent addition of the $22 \mathrm{mmol}$ of $\mathrm{BnOH}$, demonstrating that $\mathrm{BnOOH}$ is adsorbed more strongly than $\mathrm{BnOH}$. In the second experiment (Figure 10), it was observed that despite the addition of a similar amount of $\mathrm{BnOOH}(712 \mu \mathrm{mol}$ yielding a theoretical concentration of $\left.10.3 \mu \mathrm{mol} \cdot \mathrm{g}^{-1}\right)$, the concentration in solution remained below detection limit $\left(0.20 \mu \mathrm{mol} \cdot \mathrm{g}^{-1}\right)$ for the entire reaction. Since the total amount of gold present in the reactor is in all cases $41 \mu \mathrm{mol}$, we conclude that adsorption on the catalyst support is responsible for the missing quantities of $\mathrm{BnOOH}$. The adsorption on the support is captured by site coverages assuming to follow Langmuir behavior:

$$
\begin{aligned}
\theta_{\mathrm{BnOH}, \mathrm{Al}_{2} \mathrm{O}_{3}} & =\frac{K_{\mathrm{BnOH}, \mathrm{Al}_{2} \mathrm{O}_{3}}^{a d s} C_{\mathrm{BnOH}}}{1+K_{\mathrm{BnOH}, \mathrm{Al}_{2} \mathrm{O}_{3}}^{a d s} C_{\mathrm{BnOH}}+K_{\mathrm{BnOOH}, \mathrm{Al}_{2} \mathrm{O}_{3}}^{a d s} C_{\mathrm{BnOOH}}} \\
\theta_{\mathrm{BnOOH}, \mathrm{Al}_{2} \mathrm{O}_{3}} & =\frac{K_{\mathrm{BnOOH}, \mathrm{Al}_{2} \mathrm{O}_{3}}^{a d C_{\mathrm{BnOH}}}}{1+K_{\mathrm{BnOH}, \mathrm{Al}_{2} \mathrm{O}_{3}} C_{\mathrm{BnOH}}+K_{\mathrm{BnOOH}, \mathrm{Al}_{2} \mathrm{O}_{3}} C_{\mathrm{BnOOH}}}
\end{aligned}
$$

Where: $\quad \theta_{i, A_{2} O_{3}}=$ occupancy of the surface sites (-)

$K_{i, A l_{2} O_{3}}^{a d s}=$ adsorption constant of compound $i$ on the support $\left(\mathrm{g} \cdot \mathrm{mol}^{-1}\right)$ 
From these experimental data the adsorption constants $\mathrm{K}_{\mathrm{BnOH}, \mathrm{Al}_{2} \mathrm{O}_{3}}^{a d d}$ and $\mathrm{K}_{\mathrm{BnOOH}, \mathrm{Al}_{2} \mathrm{O}_{3}}^{a d s}$ were estimated to be $18.1 \mathrm{~g} \cdot \mathrm{mol}^{-1}$ and $2.47 \times 10^{4} \mathrm{~g} \cdot \mathrm{mol}^{-1}$, respectively, and the total adsorption site density was found to be $1.12 \mathrm{mmol} \cdot \mathrm{g}_{\text {cat }}{ }^{-1}$. With a specific surface area of $230 \mathrm{~m}^{2} \cdot \mathrm{g}^{-1}$ and using Avogadro's number, the corresponding site density on the support is equivalent to 2.92 sites per $\mathrm{nm}^{2}$, which is in good agreement with Matulewicz et al. [31] who report a value of $2 \mathrm{sites} / \mathrm{nm}^{2}$ for their $\gamma$-alumina.

This yields a relation between the overall acid concentration in the vessel, $C_{\mathrm{BnOOH}}$, tot, and the actual acid concentration in the liquid phase, $C_{\mathrm{BnOOH}}$ :

$$
C_{\mathrm{BnOOH}}=C_{\mathrm{BnOOH}, \mathrm{tot}}-\sigma_{\mathrm{OH}, \mathrm{Al}_{2} \mathrm{O}_{3}} \frac{w_{\text {cat }}}{w_{\text {liq }}} \frac{K_{\mathrm{BnOOH}, \mathrm{Al}_{2} \mathrm{O}_{3}} C_{\mathrm{BnOOH}}}{1+K_{\mathrm{BnOH}, \mathrm{Al}_{2} \mathrm{O}_{3}}^{a d s} C_{\mathrm{BnOH}}+K_{\mathrm{BnOOH}, \mathrm{Al}_{2} \mathrm{O}_{3}}^{a d s} C_{\mathrm{BnOOH}}}
$$

Where: $\quad C_{\mathrm{BnOOH}, \text { tot }}=\mathrm{BnOOH}$ concentration if no adsorption would take place $\left(\mathrm{mol} \cdot \mathrm{g}^{-1}\right)$

$\sigma_{O H, A l 2 O 3}=$ adsorption site concentration on the catalyst $\left(\mathrm{mol} \cdot \mathrm{g}_{\mathrm{cat}}{ }^{-1}\right)$

$w_{\text {cat }}=$ amount of catalyst in the reactor $\left(\mathrm{g}_{\mathrm{cat}}\right)$

$w_{\text {liq }}=$ amount of liquid in the reactor $(\mathrm{g})$

Since the amount of $\mathrm{BnOH}$ in the liquid phase is about three orders of magnitude larger than the amount of surface adsorption sites, the influence of $\mathrm{BnOH}$ adsorption on the concentration in the liquid phase is neglected. The actual acid concentration in the liquid phase can therefore be calculated directly from this quadratic equation with respect to $C_{\mathrm{BnOOH}}$ :

$$
C_{\mathrm{BnOOH}}=\frac{1}{2}\left(T+\sqrt{T^{2}+\frac{4 C_{\mathrm{BnOOH}, \text { tot }}\left(1+K_{\mathrm{BnOH}, \mathrm{Al}_{2} \mathrm{O}_{3}}^{\left.a d C_{\mathrm{BnOH}}\right)}\right.}{K_{\mathrm{BnOOH}, \mathrm{Al}_{2} \mathrm{O}_{3}}^{a d d}}}\right)
$$

Where: $\quad T=C_{B n O O H, t o t}-\frac{\left(1+K_{B n O H, A l_{2} O_{3}}^{a d s} C_{B n O H}\right)}{K_{B n O O H, A l}^{a d s} O_{3}}-\sigma_{O H, A l_{2} O_{3}} \frac{w_{c a t}}{w_{\text {liq }}}$

The strong adsorption of $\mathrm{BnOOH}$ could be the main cause of the very low activity of catalysts reused for the same experiment after a test in absence of a base, since it was observed that this acid remains on the catalyst during rinsing with toluene and also during boiling in water (Figure 13). The amount of $\mathrm{BnOOH}$ that remains on the catalyst in these 'second runs' (Figures 2b, 6b, 7b and 12) is not known but an estimate can be made. Assuming that the $\mathrm{BnOOH}$ concentration in the liquid equals its detection limit of $0.20 \mu \mathrm{mol} \cdot \mathrm{g}^{-1}$, a coverage of 0.88 is found from our simulations. Thus, it is tentatively concluded that although the amounts of acid formed in the previous runs is very low (often below the detection limit), the coverage is close to 1 . Since the inhibition with a reused catalyst was very small or negligible in the presence of $\mathrm{K}_{2} \mathrm{CO}_{3}$ or $\mathrm{KF}$, it was assumed for simplicity that in these cases all acid was removed, which seems acceptable in view of the time (approximately half an hour, the time needed for heating plus temperature stabilization) that the catalyst particles were in the close vicinity of the $\mathrm{K}_{2} \mathrm{CO}_{3}$ or $\mathrm{KF}$ crystals at reaction conditions $\left(80^{\circ} \mathrm{C}\right.$ and well mixed) before the $\mathrm{BnOH}$ was added.

The model also accounts for the time allowed between adding the $\mathrm{BnO}$ or the $\mathrm{BnOOH}$ to the reactor and adding the main reactant $\mathrm{BnOH}$, in all cases about $20 \mathrm{~min}$ at reaction conditions (additionally from 
the heating time). In the case of $\mathrm{BnO}$ this causes the formation of significant amounts of $\mathrm{BnOOH}$, inhibiting the reaction (Figure 3).

Besides the three rate constants $k_{1}, k_{2}, k_{3}$, and the three adsorption equilibrium constants, $K_{\mathrm{BnOOH}}$, $\mathrm{K}_{\mathrm{BnOH}, \mathrm{Al}_{2} \mathrm{O}_{3}}^{a d s}$ and $\mathrm{K}_{\mathrm{BnOOH}, \mathrm{Al}_{2} \mathrm{O}_{3}}^{a d s}$, there are several other unknown parameters, which are related to the effect of the base present. The experimental results show that the main effects of either $\mathrm{K}_{2} \mathrm{CO}_{3}$ or $\mathrm{KF}$ are (i) a decrease of the inhibition and (ii) an increase in formation of the BnOOBn ester.

In order to account for effect (i), it is assumed that the bases react to potassium benzoate with the $\mathrm{BnOOH}$ formed. Although acid-base reactions are typically instantaneous reactions, a finite rate is assumed to account for the transport from the catalyst pores to the insoluble crystals of $\mathrm{K}_{2} \mathrm{CO}_{3}$ or KF. The reaction rate is assumed to be first-order with respect to the acid and independent of the catalyst concentration:

$$
r_{\text {AcBase }}=k_{\text {AcBase }} C_{B n O O H}
$$

Effect (ii) is accounted for by defining parameters to describe the strength of either $\mathrm{K}_{2} \mathrm{CO}_{3}$ or $\mathrm{KF}$ in the catalysis of the esterification of $\mathrm{BnO}$ with $\mathrm{BnOH}$ :

$$
\begin{aligned}
& \text { No base: } S_{\text {base }}=1 \\
& \mathrm{~K}_{2} \mathrm{CO}_{3}: S_{\text {base }}=1+S_{\mathrm{K}_{2} \mathrm{CO}_{3}} \\
& \mathrm{KF}: S_{\text {base }}=1+S_{\mathrm{K}_{2} \mathrm{CO}_{3}} S_{\mathrm{KF}^{\prime} / \mathrm{K}_{2} \mathrm{CO}_{3}}
\end{aligned}
$$

$S_{K 2 C O 3}$ is defined as the base strength of $\mathrm{K}_{2} \mathrm{CO}_{3}$ and $S_{K F / K 2 C O 3}$ as the relative base strength of KF compared to $\mathrm{K}_{2} \mathrm{CO}_{3}$.

Since the experiments were performed in batch operation in a vessel that is assumed to be ideally stirred, the reactor model used to describe the process is the batch reactor model:

$$
\frac{d C_{i, L}}{d t}=C_{c a t} \sum_{j} v_{i, j} r_{j}
$$

Where: $\quad C_{i, L}=$ concentration of component $i$ in the liquid phase $\left(\mathrm{mmol} \cdot \mathrm{g}^{-1}\right)$

$t=$ time $(\mathrm{s})$

$C_{c a t}=$ catalyst concentration $\left(\mathrm{mg} \cdot \mathrm{g}^{-1}\right)$

$v_{i, j}=$ stoichiometric coefficient of component $i$ in reaction $j(-)$

$r_{j}=$ reaction rate of reaction $j\left(\mathrm{mmol} \cdot \mathrm{mg}_{\mathrm{cat}}{ }^{-1} \cdot \mathrm{s}^{-1}\right)$

The complete experimental dataset used for the parameter estimation contains 140 experimental data points obtained in 14 batch experiments at various conditions. The parameter estimation was carried out using the software package Athena Visual Studio [32], applying Bayesian estimation for multiresponse experiments using the full covariance matrix [33]. The concentrations (expressed in $\mathrm{mol} \cdot \mathrm{g}^{-1}$ ) of the four measured liquid components were used as the input for the objective function to be minimized. Since the concentrations of the $\mathrm{BnOOH}$ and the ester were typically up to two orders of magnitude smaller than those of the $\mathrm{BnOH}$ and $\mathrm{BnO}$, the weight of $\mathrm{BnOOBn}$ was set at 10 and that of $\mathrm{BnOOH}$ at 100 . For experiments with a very low conversion rate of $\mathrm{BnOH}$, the weight of $\mathrm{BnO}$ was increased to 10 as well. 
With the exception of the experiment of Figure 4, $\mathrm{BnOOH}$ concentrations were mostly below the detection limit of $0.20 \mu \mathrm{mol} \cdot \mathrm{g}^{-1}$. Since the model predictions are very sensitive to the acid concentration, it was necessary to estimate acid concentrations for experiments where these were not detectable. In those cases, acid concentrations were arbitrarily assumed to be half of the detection limit.

These data lead to fits of the seven kinetic parameters to the experimental dataset and the results are shown in Table 2.

Table 2. Optimal estimates of the kinetic parameters using all experimental data.

\begin{tabular}{|c|c|c|c|c|}
\hline \multirow{2}{*}{ Parameter } & \multirow{2}{*}{ Unit } & \multirow{2}{*}{ Estimate } & \multicolumn{2}{|c|}{$95 \%$ confidence range } \\
\hline & & & Value & Relative/\% \\
\hline$k_{1}$ & $/ \mathrm{g} \cdot \mathrm{mg}_{\mathrm{cat}}{ }^{-1} \cdot \mathrm{s}^{-1}$ & $2.69 \times 10^{-3}$ & $\pm 5.0 \times 10^{-4}$ & \pm 19 \\
\hline$k_{2}$ & $/ \mathrm{g} \cdot \mathrm{mg}_{\mathrm{cat}}{ }^{-1} \cdot \mathrm{s}^{-1}$ & $2.37 \times 10^{-4}$ & $\pm 5.9 \times 10^{-5}$ & \pm 25 \\
\hline$k_{3}$ & $/ \mathrm{g}^{2} \cdot \mathrm{mmol}^{-1} \cdot \mathrm{mg}_{\mathrm{cat}}{ }^{-1} \cdot \mathrm{s}^{-1}$ & $6.6 \times 10^{-4}$ & $\pm 3.5 \times 10^{-4}$ & \pm 54 \\
\hline $\boldsymbol{k}_{\text {AcBase }}$ & $/ \mathrm{s}^{-1}$ & 0.71 & \pm 0.15 & \pm 21 \\
\hline $\boldsymbol{K}_{\text {BnоOH }}$ & $/ \mathrm{g} \cdot \mathrm{mmol}^{-1}$ & $1.23 \times 10^{4}$ & $\pm 1.5 \times 10^{3}$ & \pm 12 \\
\hline $\mathrm{K}_{\mathrm{BnOH}, \mathrm{Al}_{2} \mathrm{O}_{3}}^{a d s}$ & $\mathrm{~g} \cdot \mathrm{mmol}^{-1}$ & 18.1 & fixed & \\
\hline $\mathrm{K}_{\mathrm{BnOOH}, \mathrm{Al}_{2} \mathrm{O}_{3}}^{a d s}$ & $\mathrm{~g} \cdot \mathrm{mmol}^{-1}$ & $2.47 \times 10^{4}$ & fixed & \\
\hline$S_{\mathrm{K} 2 \mathrm{CO} 3}$ & /- & 1.39 & \pm 0.81 & \pm 58 \\
\hline$S_{K F / K 2 C O 3}$ & /- & 1.37 & \pm 0.39 & \pm 29 \\
\hline$S S R^{*}$ & /- & 0.414 & - & - \\
\hline
\end{tabular}

$\left(^{*}\right) S S R=\sum_{i=1}^{v} w_{i} \sum_{k=1}^{n}\left(C_{i, k, \exp }-C_{i, k, \bmod }\right)^{2}$ (sum of the squared residuals) $\left(w_{i}=\right.$ weight factor for response $i$, $v=$ number of responses, $C_{i, k \text {, exp }}=$ experimental response of component $i$ in experiment $k, C_{i, k, \text { mod }}=$ model response of component $i$ in experiment $k, n=$ number of experiments (samples).

While relatively good fits of predicted concentrations of $\mathrm{BnOH}$, benzaldehyde and $\mathrm{BnOOBn}$ with time are evident in Figures $2 \mathrm{a}$ and $6 \mathrm{a}$ for first batch runs with and without $\mathrm{K}_{2} \mathrm{CO}_{3}$, relatively poor fits of benzaldehyde concentration are observed for second-time runs (Figures $2 b$ and $6 b$ ) and the first run with KF (Figure 7a). The poorer fit of the second runs in the presence of $\mathrm{K}_{2} \mathrm{CO}_{3}$ is understandable since it was assumed in the model that all $\mathrm{BnOOH}$ was removed by the base in between the experiments, which is probably not completely justified, indicating that some acid or another inhibiting species remains on the catalyst. In all other experiments, approximate fits of concentrations of one or both products or of all three species (alcohol, aldehyde and ester) are observed (see Figures 3, 4, 7b, and 10-12). Thus, variations in how well the fit follows the data are a logical consequence of attempting to simulate in a single model a wide range of concentrations with and without base and in the absence and presence of strongly inhibiting aldehyde and acid product species. Moreover, the model did not include effects of water and was limited to the three most important reactions and four most important species. The $54 \%$ and $58 \%$ relative confidence intervals for $k_{3}$ and $S_{\mathrm{K} 2 \mathrm{CO} 3}$ originate from the strong correlation between these two parameters, which is discussed later in this section. The approximate nature of the model can be attributed to: 
(1) Assumptions that are only approximately valid, e.g., (a) arbitrary estimates of benzoic acid concentration, and (b) the assumption that benzoic acid is completely removed from the catalyst by interaction with insoluble $\mathrm{K}_{2} \mathrm{CO}_{3}$ or $\mathrm{KF}$ crystals.

(2) By practical necessity, the limited scope of the mechanistic scheme, e.g., (a) neglecting effects of adsorption or inhibition of some species such as coverages of $\mathrm{BnOH}$ of $\mathrm{BnOOBn}$ and (b) neglecting the positive effect of water.

Nevertheless, the model provides (1) accurate predictions of initial reaction rate for oxidation of $\mathrm{BnOH}$ to $\mathrm{BnO}$ on a gold/alumina catalyst and (2) approximate predictions of the effects of $\mathrm{BnOOH}$ inhibition and the neutralizing effect of potassium salts to alleviate this inhibition.

The value of the rate constant for the reaction of the $\mathrm{BnOOH}$ with the base to potassium benzoate, $k_{\text {AcBase }}$, represents the characteristic time for the transport of $\mathrm{BnOOH}$ from a catalytic site to the $\mathrm{K}_{2} \mathrm{CO}_{3}$ or KF crystals. The order of magnitude can be compared with an estimate of the characteristic time for diffusion [34] of $\mathrm{BnOOH}$ through the catalyst pores to the liquid bulk, obtained from a typical diffusion distance (one third of the catalyst particle size $50 \mu \mathrm{m}$, estimated from the sieve mesh size) and an effective diffusivity of $4.8 \times 10^{-10} \mathrm{~m}^{2} \cdot \mathrm{s}^{-1}$ (estimated using Wilke and Chang's relationship [35], using porosity-tortuosity ratio of 0.14 , based on data of similar aluminas and catalysts):

$$
\tau_{\text {diff }, \mathrm{BnOOH}}=\frac{\left(\frac{1}{3} d_{p}\right)^{2}}{2 \times D_{\text {eff }, \mathrm{BnOOH}}}
$$

Where: $\quad \tau_{\text {diff,BnOOH }}=$ diffusion time $(\mathrm{s})$

$d_{p}=$ catalyst particle diameter $(\mathrm{m})$

$D_{\text {eff, }, \text { BnOOH }}=$ effective diffusivity $\left(\mathrm{m}^{2} \cdot \mathrm{s}^{-1}\right)$

This yields a typical diffusion time of $0.3 \mathrm{~s}$, which is about 4.8 times smaller than the typical time $\left(k_{\text {AcBase }}\right)^{-1}=1.41 \mathrm{~s}$. The latter seems a plausible value in view of the additional transport resistance that might be caused by the transfer from the external catalyst surface towards the $\mathrm{K}_{2} \mathrm{CO}_{3}$ or $\mathrm{KF}$ crystals.

The correlation matrix for the estimated parameters, shown in Table 3, shows that the strongest correlation occurs between $k_{3}$ and $S_{\mathrm{K} 2 \mathrm{CO} 3}$ with a correlation coefficient of -0.97 , which is in line with our conclusion that the ester formation in our system is base-catalyzed. All correlations between the parameters justify maintaining all parameters in the model since these do not exceed the value of 0.99 , which is accepted as the limit for a proper parameter estimation [36].

Table 3. Correlation matrix between all the parameters estimated using the optimized kinetic model.

\begin{tabular}{cccccccc}
\hline Parameter & $\mathbf{k}_{\mathbf{1}}$ & $\mathbf{k}_{\mathbf{2}}$ & $\mathbf{k}_{\mathbf{3}}$ & $\mathbf{k}_{\mathbf{A c B a s e}}$ & $\mathbf{K}_{\mathbf{B n O O H}}$ & $\mathbf{S}_{\mathbf{K} 2 \mathrm{CO} 3}$ & $\mathbf{S}_{\mathbf{K F} / \mathbf{K} \mathbf{C O} \mathbf{3}}$ \\
\hline$k_{1}$ & 1 & & & & & & \\
$k_{2}$ & 0.52 & 1 & & & & & \\
$k_{3}$ & 0.06 & -0.13 & 1 & & & & \\
$k_{\mathrm{AcBase}}$ & 0.12 & -0.17 & -0.02 & 1 & & & \\
$K_{\mathrm{BnOOH}}$ & 0.51 & -0.30 & 0.09 & 0.64 & 1 & & \\
$S_{\mathrm{K} 2 \mathrm{CO} 3}$ & 0.02 & 0.12 & -0.97 & 0.06 & -0.01 & 1 & \\
$S_{\mathrm{KF} / \mathrm{K} 2 \mathrm{CO} 3}$ & -0.01 & -0.02 & 0.33 & -0.05 & -0.01 & -0.45 & 1 \\
\hline
\end{tabular}




\section{Experimental Section}

Toluene (anhydrous, 99.8\%), benzyl alcohol ( $>99 \%$ ), potassium carbonate $(>99.0 \%)$, tetradecane ( $>99 \%$ ), potassium fluoride ( $>99.99 \%$ ) and phosphorus pentoxide desiccant were supplied by Sigma Aldrich and were used without further purification. AUROlite ${ }^{\mathrm{TM}}$ catalyst $\left(\mathrm{Au} / \mathrm{Al}_{2} \mathrm{O}_{3} 1 \mathrm{wt} . \%, \mathrm{Au}\right.$ average particle size: $2-3 \mathrm{~nm}$, specific surface area: $200-260 \mathrm{~m}^{2} \cdot \mathrm{g}^{-1}$, from supplier specifications) was supplied by Strem Chemicals in the form of extrudates. The extrudates were crushed and sieved to a particle size $<71 \mu \mathrm{m}$, thereby excluding diffusion limitations during catalytic experiments as verified using different catalyst particle sizes. The resulting powder was stored in a well-sealed container at $4{ }^{\circ} \mathrm{C}$ and in the dark. Catalytic testing under dry conditions was performed with this powder used as such. For the catalytic tests involving water, the desired amount of this powder was suspended in Milli- $Q^{\circledR}$ water $(18.2 \mathrm{M} \Omega \cdot \mathrm{cm})$ under sonication for $30 \mathrm{~min}$, and then vacuum filtered (using a Büchner funnel). The resulting moist catalyst was collected from the filter with a spatula and used as such for catalytic testing. The mass difference before and after this step indicates that around $0.5 \mathrm{~g}$ of water is adsorbed per gram of catalyst.

Catalytic experiments were carried out in a $100 \mathrm{~mL}$ round-bottom vessel, the inner diameter of which is $60 \mathrm{~mm}$. The vessel was equipped with a reflux condenser and Teflon baffles, and mechanically stirred at $1300 \mathrm{rpm}$ with a 4-blade Teflon impeller. Upon varying the catalyst quantity in preliminary tests, an initial reaction rate proportional to the catalyst quantity was observed, indicating that mass transport limitations were absent. In a typical catalytic test, $3.04 \mathrm{~g} \mathrm{of} \mathrm{K}_{2} \mathrm{CO}_{3}$ and $0.8 \mathrm{~g}$ of AUROlite $^{\mathrm{TM}}$ are introduced in the vessel together with $80 \mathrm{~mL}$ of toluene. Two complementary tests were performed using $2.07 \mathrm{~g}$ of $\mathrm{KF}$ instead of $\mathrm{K}_{2} \mathrm{CO}_{3}$. The vessel was heated to $80{ }^{\circ} \mathrm{C}$ by means of an oil bath, and $200 \mathrm{~mL} \cdot \mathrm{min}^{-1}$ of air was bubbled through the reaction mixture via a glass frit. When the temperature was stabilized, $2.4 \mathrm{~g}$ of $\mathrm{BnOH}$ was introduced using a syringe, constituting the beginning of the test $(t=0 \mathrm{~min})$. Small samples of $300 \mu \mathrm{L}$ were taken at recorded times and filtered from catalyst and $\mathrm{K}_{2} \mathrm{CO}_{3}$ powders with a $13 \mathrm{~mm}$ syringe Teflon filter of $0.2 \mu \mathrm{m}$ pore size (diameter: $13 \mathrm{~mm}$; pore size: $0.2 \mu \mathrm{m}$; PTFE membrane; VWR International) and introduced in a GC sample vial together with $20 \mu \mathrm{L}$ of tetradecane, the latter being used as internal standard.

GC analyses were performed using a Varian CP-3380 equipped with a FID detector and a CP-Sil 8 $\mathrm{CB}$ cat. no. 7453 column (length: $50 \mathrm{~m}$; diameter: $0.25 \mathrm{~mm}$; coating thickness: $0.25 \mu \mathrm{m}$ ). The initial temperature of the $\mathrm{GC}$ oven was $150{ }^{\circ} \mathrm{C}$ and was maintained for $4 \mathrm{~min}$, then increased with $100^{\circ} \mathrm{C} \cdot \mathrm{min}^{-1}$ to $220{ }^{\circ} \mathrm{C}$ and then maintained at $220^{\circ} \mathrm{C}$ for $6.3 \mathrm{~min}$. After testing, the catalyst was recovered by vacuum filtration, washed with $80 \mathrm{~mL}$ of toluene at room temperature and stored over $\mathrm{P}_{2} \mathrm{O}_{5}$ in an evacuated desiccator. In the case of the water treated catalyst samples, the catalyst was washed with $80 \mathrm{~mL}$ of toluene, followed by extensive washing with about $250 \mathrm{~mL}$ of Milli- $\mathrm{Q}^{\circledR}$ water $(18.2 \mathrm{M} \Omega \cdot \mathrm{cm})$ at room temperature.

Diffuse Reflectance Infra-Red Fourier Transform Spectroscopy (DRIFTS) spectra were recorded on a Nicolet model 8700 spectrometer, equipped with a high-temperature DRIFTS cell, and a DTGS-TEC detector. The spectra were recorded with 256 scans at $4 \mathrm{~cm}^{-1}$ resolution from 4000 to $500 \mathrm{~cm}^{-1}$ using potassium bromide $(\mathrm{KBr})$ to perform background subtraction. The samples were pre-treated at $473 \mathrm{~K}$ for $1 \mathrm{~h}$ in a helium flow of $20 \mathrm{~mL} \cdot \mathrm{min}^{-1}$. 


\section{Conclusions}

Our study shows that benzoic acid or compounds formed from benzoic acid cause catalyst inhibition in benzyl alcohol oxidation in toluene and in absence of a base. The introduction of a potassium salt as a base prevents this inhibition by neutralizing the benzoic acid formed. Basic conditions result in a decrease in selectivity to benzaldehyde and in an increase of ester production. The enhanced ester formation probably occurs via condensation of alkoxy species (formed by alcohol deprotonation by the base) with benzaldehyde under oxidative conditions, and is not the result of an increased benzoic acid production followed by esterification, as might be expected under acidic conditions. Water appears to have no influence on inhibition, but may enhance the effect of the base described above by improved dissolution. Although effects of water were not modeled, a kinetic effect for water cannot be excluded.

The concentration versus time data of the batch experiments in this study, which covered a wide range and included effects of acid inhibition and base, were fitted to a comprehensive kinetic model for (1) the primary reaction, oxidation of benzyl alcohol to benzaldehyde; (2) secondary oxidation of benzaldehyde to benzoic acid; and (3) secondary esterification of benzyl alcohol and benzaldehyde to benzyl benzoate. Effects of base (potassium salts) were also included in the model. The resulting model predicts concentration-time trends approximately well, including inhibition by benzoic acid and the neutralization of benzoic acid by potassium salts, forming potassium benzoate. A precise fit of the model to experimental data was observed in two first batch runs, with and without $\mathrm{K}_{2} \mathrm{CO}_{3}$. Variations in how well the fit follows the data are a logical consequence of attempting to simulate in a single model a wide range of concentrations with and without base and in the absence and presence of product species such as aldehyde and strongly inhibiting acid. Moreover, the model did not include effects of water and was limited to the three most important reactions and four most important species.

Nevertheless, the model provides (1) accurate predictions of initial reaction rate for oxidation of benzyl alcohol to benzaldehyde on a gold/alumina catalyst and (2) approximate predictions of the effects of benzoic acid inhibition and the neutralizing effect of a potassium base to alleviate this inhibition.

\section{Acknowledgments}

The Dutch National Research School Combination Catalysis Controlled by Chemical Design (NRSC-Catalysis) is gratefully acknowledged for financial support.

\section{Conflict of Interest}

The authors declare no conflict of interest.

\section{References}

1. Davis, S.E.; Ide, M.S.; Davis, R.J. Selective oxidation of alcohols and aldehydes over supported metal nanoparticles. Green Chem. 2013, 15, 17-45.

2. Lilga, M.A.; Hallen, R.T.; Gray, M. Production of oxidized derivatives of 5-Hydroxymethylfurfural (HMF). Topics Catal. 2010, 53, 1264-1269. 
3. Zope, B.N.; Davis, R.J. Inhibition of gold and platinum catalysts by reactive intermediates produced in the selective oxidation of alcohols in liquid water. Green Chem. 2011, 13, 3484-3491.

4. Haruta, M.; Yamada, N.; Kobayashi, T.; Iijima, S. Gold catalysts prepared by coprecipitation for low-temperature oxidation of hydrogen and of carbon monoxide. J. Catal. 1989, 115, 301-309.

5. Alhumaimess, M.; Lin, Z.; Weng, W.; Dimitratos, N.; Dummer, N.F.; Taylor, S.H.; Bartley, J.K.; Kiely, C.J.; Hutchings, G.J. Oxidation of benzyl alcohol by using gold nanoparticles supported on ceria foam. ChemSusChem 2012, 5, 125-131.

6. Deplanche, K.; Mikheenko, I.P.; Bennett, J.A.; Merroun, M.; Mounzer, H.; Wood, J.; MacAskie, L.E. Selective oxidation of benzyl-alcohol over biomass-supported Au/Pd bioinorganic catalysts. Topics Catal. 2011, 54, 1110-1114.

7. Guo, H.; Kemell, M.; Al-Hunaiti, A.; Rautiainen, S.; Leskelä, M.; Repo, T. Gold-palladium supported on porous steel fiber matrix: Structured catalyst for benzyl alcohol oxidation and benzyl amine oxidation. Catal. Commun. 2011, 12, 1260-1264.

8. Guo, H.; Al-Hunaiti, A.; Kemell, M.; Rautiainen, S.; Leskelä, M.; Repo, T. Gold catalysis outside nanoscale: Bulk gold catalyzes the aerobic oxidation of $\pi$-activated alcohols. ChemCatChem 2011, 3, 1872-1875.

9. Hao, Y.; Hao, G.P.; Guo, D.C.; Guo, C.Z.; Li, W.C.; Li, M.R.; Lu, A.H. Bimetallic Au-Pd Nanoparticles Confined in Tubular Mesoporous Carbon as Highly Selective and Reusable Benzyl Alcohol Oxidation Catalysts. ChemCatChem 2012, 4, 1595-1602.

10. Heeskens, D.; Aghaei, P.; Kaluza, S.; Strunk, J.; Muhler, M. Selective oxidation of ethanol in the liquid phase over $\mathrm{Au} / \mathrm{TiO}_{2}$. Phys. Status Solidi. A 2013, 250, 1107-1118.

11. Mallat, T.; Baiker, A. Oxidation of alcohols with molecular oxygen on solid catalysts. Chem. Rev. 2004, 104, 3037-3058.

12. Quintanilla, A.; Butselaar-Orthlieb, V.C.L.; Kwakernaak, C.; Sloof, W.G.; Kreutzer, M.T.; Kapteijn, F. Weakly bound capping agents on gold nanoparticles in catalysis: Surface poison? $J$. Catal. 2010, 271, 104-114.

13. Sá, J.; Taylor, S.F.R.; Daly, H.; Goguet, A.; Tiruvalam, R.; He, Q.; Kiely, C.J.; Hutchings, G.J.; Hardacre, C. Redispersion of gold supported on oxides. ACS Catal. 2012, 2, 552-560.

14. Mallat, T.; Baiker, A. Oxidation of alcohols with molecular oxygen on platinum metal catalysts in aqueous solutions. Catal. Today 1994, 19, 247-283.

15. Zope, B.N.; Hibbitts, D.D.; Neurock, M.; Davis, R.J. Reactivity of the gold/water interface during selective oxidation catalysis. Science 2010, 330, 74-78.

16. Moulijn, J.A.; van Diepen, A.E.; Kapteijn, F. Catalyst deactivation: Is it predictable? What to do? Appl. Catal. 2001, 212, 3-16.

17. Keresszegi, C.; Bürgi, T.; Mallat, T.; Baiker, A. On the role of oxygen in the liquid-phase aerobic oxidation of alcohols on palladium. J. Catal. 2002, 211, 244-251.

18. Dimitratos, N.; Villa, A.; Wang, D.; Porta, F.; Su, D.; Prati, L. Pd and Pt catalysts modified by alloying with $\mathrm{Au}$ in the selective oxidation of alcohols. J. Catal. 2006, 244, 113-121.

19. Rodríguez-Reyes, J.C.F.; Friend, C.M.; Madix, R.J. Origin of the selectivity in the gold-mediated oxidation of benzyl alcohol. Surf. Sci. 2012, 606, 1129-1134. 
20. Fang, W.; Chen, J.; Zhang, Q.; Deng, W.; Wang, Y. Hydrotalcite-supported gold catalyst for the oxidant-free dehydrogenation of benzyl alcohol: Studies on support and gold size effects. Chem. A Eur. J. 2011, 17, 1247-1256.

21. Kimling, J.; Maier, M.; Okenve, B.; Kotaidis, V.; Ballot, H.; Plech, A. Turkevich method for gold nanoparticle synthesis revisited. J. Phys. Chem. B 2006, 110, 15700-15707.

22. Juan-Alcañiz, J.; Ferrando-Soria, J.; Luz, I.; Serra-Crespo, P.; Skupien, E.; Santos, V.P.; Pardo, E.; Llabrés i Xamena, F.X.; Kapteijn, F.; Gascon, J. The oxamate route, a versatile post-functionalization for metal incorporation in MIL-101(Cr): Catalytic applications of $\mathrm{Cu}, \mathrm{Pd}$, and $\mathrm{Au} . J$. Catal. 2013, 307, 295-304.

23. Fristrup, P.; Johansen, L.B.; Christensen, C.H. Mechanistic investigation of the gold-catalyzed aerobic oxidation of alcohols. Catal. Lett. 2008, 120, 184-190.

24. Abad, A.; Corma, A.; García, H. Catalyst parameters determining activity and selectivity of supported gold nanoparticles for the aerobic oxidation of alcohols: The molecular reaction mechanism. Chem. A Eur. J. 2008, 14, 212-222.

25. Pina, C.D.; Falletta, E.; Rossi, M. Update on selective oxidation using gold. Chem. Soc. Rev. 2012, 41, 350-369.

26. Daté, M.; Okumura, M.; Tsubota, S.; Haruta, M. Vital role of moisture in the catalytic activity of supported gold nanoparticles. Angew. Chem. Int. Ed. 2004, 43, 2129-2132.

27. Daniells, S.T.; Overweg, A.R.; Makkee, M.; Moulijn, J.A. The mechanism of low-temperature $\mathrm{CO}$ oxidation with $\mathrm{Au} / \mathrm{Fe}_{2} \mathrm{O}_{3}$ catalysts: A combined Mössbauer, FT-IR, and TAP reactor study. J. Catal. 2005, 230, 52-65.

28. Yang, X.; Wang, X.; Liang, C.; Su, W.; Wang, C.; Feng, Z.; Li, C.; Qiu, J. Aerobic oxidation of alcohols over $\mathrm{Au} / \mathrm{TiO}_{2}$ : An insight on the promotion effect of water on the catalytic activity of $\mathrm{Au} / \mathrm{TiO}_{2}$. Catal. Commun. 2008, 9, 2278-2281.

29. Chang, C.R.; Yang, X.F.; Long, B.; Li, J. A water-promoted mechanism of alcohol oxidation on a $\mathrm{Au}(111)$ surface: Understanding the catalytic behavior of bulk gold. ACS Catal. 2013, 3, 1693-1699.

30. Socrates, G. Infrared and Raman Characteristic Group Frequencies. Tables and Charts, 3rd ed.; John Wiley \& Sons Ltd: Heidelberg, Germany, 2004; pp. 50-167.

31. Matulewicz, E.R.A.; Kerkhof, F.P.J.M.; Moulijn, J.A.; Reitsma, H.J. Structure and activity of fluorinated alumina. 1. Determination of the number of protonic sites by an infrared study of adsorbed pyridines. J. Colloid Interface Sci. 1980, 77, 110-119.

32. Athena Visual Studio, Software for Modeling, Estimation and Optimization, Version 14.2. Available online: www.AthenaVisual.com 1997-2009 (accessed 25 September 2013).

33. Stewart, W.E.; Caracotsios, M.; Sorensen, J.P. Parameter estimation from multiresponse data. AIChE J. 1992, 38, 641-650.

34. Atkins, P.W. Physical Chemistry, 5th ed.; W.H. Freeman: New York, NY, USA, 1994.

35. Perry, R.H.; Green, D.W. Perry's Chemical Engineers' Handbook, 7th ed.; McGraw-Hill: New York, NY, USA, 1997. 
36. Stewart, W.E.; Caracotsios M. Computer-Aided Modelling of Reactive Systems; John Wiley \& Sons, Inc., Hoboken, NJ, USA, 2008.

(C) 2014 by the authors; licensee MDPI, Basel, Switzerland. This article is an open access article distributed under the terms and conditions of the Creative Commons Attribution license (http://creativecommons.org/licenses/by/3.0/). 